\title{
Retos a la hora de optimizar los programas de protección social y reducir la vulnerabilidad en América Latina y el Caribe ${ }^{1}$
}

\author{
Javier Bronfman $\mathrm{H}$.
}

\section{Resumen}

Este artículo ofrece un análisis reflexivo sobre el diseño e implementación de los sistemas de protección social y los programas para combatir la pobreza en América Latina y el Caribe. Se centra particularmente en la expansión de los programas de transferencias condicionadas y de pensiones no contributivas aplicados en los últimos decenios. El objetivo de este estudio es extraer lecciones sobre estas políticas y fomentar el debate sobre los retos y las oportunidades que ofrece la Agenda 2030 para el Desarrollo Sostenible en cuanto a los sistemas de protección social. Se sostiene que hacer más de lo mismo no será suficiente para preservar el progreso y alcanzar un mayor grado de desarrollo en el futuro. Por medio de ejemplos, se estudian los retos que plantea el paradigma de la Agenda 2030 para el Desarrollo Sostenible, como los grupos excluidos, las necesidades que surgen a lo largo del ciclo vital, las restricciones fiscales y una mejor coordinación entre los sectores. El artículo concluye con una serie de preguntas para profundizar el debate y una conclusión con recomendaciones sobre las políticas.

\section{Palabras clave}

Seguridad social, mitigación de la pobreza, política social, Agenda 2030 para el Desarrollo Sostenible, ingresos, pensiones, programas de acción, reforma administrativa, igualdad, América Latina y el Caribe

\section{Clasificación JEL}

I3, $\mathrm{HO}, \mathrm{H} 4$

\section{Autor}

Javier Bronfman $\mathrm{H}$. es Ingeniero Comercial y Doctor en Administración y Política Pública por la American University de los Estados Unidos y Profesor Asistente de la Facultad de Economía y Negocios de la Universidad Andrés Bello de Chile. Correo electrónico: javier.bronfman@unab.cl.

\footnotetext{
El autor agradece las observaciones sobre este artículo recibidas del personal del Programa de las Naciones Unidas para el Desarrollo (PNUD) y de los colegas de la Escuela de Gobierno de la Universidad Adolfo Ibáñez, Chile, a la que estaba vinculado cuando este artículo fue aceptado para su publicación. Los errores que pueda haber son responsabilidad del autor.
} 


\section{Introducción}

En este artículo se ofrece un análisis del diseño e implementación de los sistemas de protección social y los programas para combatir la pobreza en América Latina y el Caribe, con el fin de aprender del pasado y mejorar las políticas en el futuro. El análisis tiene por objeto extraer mensajes sobre las políticas y fomentar un debate fructífero sobre los retos y las oportunidades que plantea una nueva generación de sistemas de protección social a la luz de la Agenda 2030 para el Desarrollo Sostenible.

Si bien hay diversas definiciones de protección social, todas coinciden en que los sistemas de protección social incluyen políticas y programas para hacer frente a la pobreza y la vulnerabilidad. El Programa de las Naciones Unidas para el Desarrollo (PNUD) brinda una definición operacional de los sistemas de protección social al señalar que son sistemas que permiten proporcionar apoyo contributivo y no contributivo a los ingresos para reducir y prevenir la pobreza; garantizar que todos, en especial los grupos tradicionalmente vulnerables o excluidos, puedan acceder a los servicios sociales básicos; estimular la inclusión productiva mediante el fomento de las capacidades, las habilidades, los derechos y las oportunidades de las personas en situación de pobreza y exclusión; crear resiliencia y proteger a las personas frente a los riesgos asociados a la perturbación de sus medios de subsistencia a lo largo del ciclo de vida, y contribuir a eliminar las barreras estructurales, incluidas las de dentro del hogar, que impiden a las personas alcanzar el bienestar (PNUD, 2016c, pág. 16).

Para hacer frente a la desigualdad en sus múltiples formas, los sistemas de protección social constan de tres elementos: asistencia social, seguro social y políticas dirigidas al mercado laboral (Barrientos, 2011). La desigualdad se puede determinar por medio de una matriz que se compone de cuatro ejes: i) nivel socioeconómico; ii) género, raza y origen étnico; iii) etapas del ciclo de vida, y iv) heterogeneidades territoriales (CEPAL, 2016, pág. 16). Estas variables están naturalmente interconectadas: es fácil ver cómo el aumento de una puede incidir en las demás.

Los sistemas de protección social se han impuesto en todo el mundo como una forma de reducir y prevenir la pobreza ayudando a las personas a mitigar su exposición a los riesgos y a amortiguar los choques negativos. En estos sistemas también se han incorporado inversiones en capital humano que han fomentado el desarrollo de las personas y han permitido cortar el círculo vicioso de la pobreza. Sin embargo, persisten varios retos. Si bien los sistemas de protección social tienen potencial, los programas actuales no son lo suficientemente vigorosos como para garantizar que se alcancen las metas de los Objetivos de Desarrollo Sostenible (ODS).

Es necesario introducir reformas para apuntalar el progreso multidimensional y lograr un desarrollo sostenible. Es preciso ampliar la protección social y garantizar un piso mínimo de prestaciones para mitigar los riesgos que surgen en el ciclo de vida y proteger a la creciente población vulnerable de la región. También hay que prestar atención a los grupos que históricamente han sido excluidos o estigmatizados, como las poblaciones indígenas, las mujeres, y las personas lesbianas, gais, bisexuales, transgénero e intersexuales (LGBTI), abordando los factores estructurales que limitan la expansión de la cobertura y teniendo en cuenta el entorno en todo el proceso de reforma.

En la próxima sección se contextualiza el estado de desarrollo regional de América Latina y el Caribe presentando datos sobre las tendencias de desarrollo de los dos últimos decenios. En la sección III se analizan brevemente las reformas anteriores de la protección social y se hace hincapié en la expansión de los programas de transferencias condicionadas y de pensiones no contributivas que se han aplicado en los dos últimos decenios. En la sección IV se plantean una serie de retos clave para el sistema de protección social, y en la última sección se brinda una conclusión. 


\section{América Latina y el Caribe: logros y tendencias de desarrollo del pasado}

Desde la Declaración del Milenio de 2000, en que se definieron los Objetivos de Desarrollo del Milenio, América Latina y el Caribe ha prosperado. En la región se han conseguido importantes logros en la reducción de la pobreza, la paridad de género, la mejora de la situación sanitaria y el bienestar general. Según el Informe de 2015 sobre los Objetivos de Desarrollo del Milenio, en América Latina y el Caribe se alcanzó la meta de reducir a la mitad la tasa de pobreza extrema. El porcentaje de personas que vivían con menos de 1,25 dólares por día se redujo del 13\% en 1990 al 4\% en 2015. El acceso al agua potable aumentó 10 puntos porcentuales hasta llegar al 95\%, y el número de personas que no tenían acceso al saneamiento básico se redujo casi a la mitad (Naciones Unidas, 2015).

También abundan los logros en materia de salud y acceso a los servicios. La tasa de malnutrición se redujo de un 15\% en 1990 a un 6\% en 2015. La tasa de mortalidad de los menores de 5 años disminuyó drásticamente y se superó el objetivo de reducirla dos tercios. La mortalidad materna, en cambio, sigue siendo elevada en muchos países de la región (Naciones Unidas, 2015). También se ha avanzado en el control de la epidemia de VIH/sida, y las infecciones por el VIH entre los niños han disminuido gracias a los programas destinados a prevenir la transmisión maternoinfantil. Entre los adultos, sin embargo, la tasa de nuevas infecciones aumentó un 3\% entre 2010 y 2015, y las infecciones siguen concentrándose en los hombres homosexuales, las personas transgénero, los trabajadores y las trabajadoras sexuales (ONUSIDA, 2016), y los jóvenes del Caribe. En lo que atañe a la matrícula escolar y la participación en el mercado laboral, casi se ha alcanzado la paridad de género.

Sin embargo, en la mayoría de los países hay grupos que, debido a la discriminación por motivos de género, origen étnico y raza, han quedado excluidos de esta realidad. Los indígenas y los afrodescendientes, por ejemplo, han sido objeto de discriminación desde el período de la colonización (CEPAL y otros, 2018). Desde 1948 se han puesto en marcha varios programas e iniciativas para el reconocimiento de sus derechos en términos de igualdad; no obstante, ese objetivo sigue siendo un elemento clave de la matriz de la desigualdad social (CEPAL, 2016). Aunque se ha hecho un esfuerzo por recopilar mejores datos sobre estos grupos, siguen estando infrarrepresentados en las instituciones públicas y sobrerrepresentados en los deciles más pobres de la distribución de la renta. Además, debido a la segregación territorial, suelen carecer de acceso a los servicios básicos (CEPAL, 2016), y también se encuentran entre los grupos de menor nivel educativo, a pesar de los esfuerzos que se llevaron a cabo en la década de 1970 por introducir la educación bilingüe (CEPAL, 2016). A otras minorías, como las personas transgénero, no se les emiten documentos legales de identificación en que se reconozca su identidad de género, lo que les impide concluir la educación básica².

Cabe destacar que en la región de América Latina y el Caribe hay más niñas que niños matriculados en la enseñanza secundaria, un logro único en el mundo. Sin embargo, los logros educativos no siempre se traducen en oportunidades de empleo formal y de calidad. A pesar de que la participación femenina en el mercado laboral ha aumentado, entre las mujeres sigue habiendo mayores tasas de desempleo, subempleo, discriminación e informalidad, sobre todo entre las indígenas, que ya de por sí suelen enfrentar brechas de género más grandes que el resto de las mujeres. Si bien América Latina y el Caribe es la región en desarrollo del mundo donde la representación femenina en el parlamento es mayor, las mujeres siguen estando infrarrepresentadas ${ }^{3}$. También tienen más probabilidades de vivir en la pobreza que los hombres: la relación entre las mujeres y los hombres que viven en hogares

\footnotetext{
2 El hecho de que la mayoría de las personas transgénero de América Latina no hayan concluido el nivel básico de educación se contradice con la obligación de garantizar la educación primaria, reconocida en el artículo 13, párrafo 2 a) del Pacto Internacional de Derechos Económicos, Sociales y Culturales (Rachid y Massenzio, 2014, pág. 31).

3 Representan solo el $27 \%$.
} 
pobres pasó de 108 mujeres por cada 100 hombres en 1997 a 117 mujeres por cada 100 hombres en 2012 (Naciones Unidas, 2015).

También es importante reconocer que los éxitos alcanzados a escala regional no representan todo el panorama. La reducción de la pobreza extrema no ha sido uniforme en todos los países y subregiones, ni dentro de ellos. Si bien es cierto que en el conjunto de la región la pobreza extrema disminuyó de un 12\% a un 4\% entre 1990 y 2015, en los países del Caribe hubo una reducción de 11 puntos porcentuales en ese período, y en 2015 se alcanzó un nivel del 22\%. Mientras que según los últimos datos la prevalencia de la subalimentación en toda la región es inferior al 5\%, en el Caribe la tasa es del $20 \%$.

Desde 1990, la pobreza monetaria ha disminuido gradualmente en la mayoría de los países de América Latina y el Caribe. Sin embargo, en algunos casos, como Bolivia (Estado Plurinacional de), Colombia, México y el Perú, la pobreza aumentó entre 1990 y 2000, para luego disminuir hasta 2015. En Belice, entre 2002 y 2009 la pobreza general y la extrema aumentaron de un 34\% a un $42 \%$ y de un $11 \%$ a un 16\%, respectivamente (Gobierno de Belice/CARIBANK, 2010) ${ }^{4}$. Las tasas de pobreza multidimensional también varían significativamente de un país a otro ${ }^{5}$. En Haití, el 50\% de la población vive en situación de pobreza multidimensional; en Barbados y Santa Lucía, la cifra es inferior al 1\%.

Incluso dentro de los países la pobreza multidimensional es más frecuente entre determinados grupos. En dos estudios recientes se informa de una mayor prevalencia entre las poblaciones indígenas de Chile (Bronfman, 2014; Bronfman y Hadad, 2018). En ambos se estima que las tasas de pobreza multidimensional en el pueblo mapuche de ese país son mucho más altas que en el resto de la población, incluso cuando se tienen en cuenta las condiciones de vida de este grupo (Bronfman y Hadad, 2018) ${ }^{6}$. Estos resultados apoyan la idea de que las minorías raciales siguen siendo objeto de desigualdades sociales y económicas que tienen sus raíces en el pasado. Es preciso dar a estos grupos un mayor reconocimiento, sobre todo en los datos estadísticos, para contribuir a proteger sus derechos. En Bolivia (Estado Plurinacional de), el Brasil y el Ecuador recientemente se ha avanzado en la dirección correcta al reconocer los derechos de los pueblos indígenas en la Constitución (CEPAL y otros, 2018).

Muchas de las 72 millones de personas que salieron de la pobreza en América Latina y el Caribe en el último decenio han vuelto a ser vulnerables a ella ${ }^{8}$. Según el PNUD, el 38,4\% de la población de la región podría caer en la pobreza en el futuro próximo (PNUD, 2016a). Esta vulnerabilidad no es tan solo una cuestión de ingresos, sino que implica también otros indicadores de desarrollo que posiblemente reflejen la discriminación social (López-Calva y otros, 2014; PNUD, 2016a)9. Gran parte de la población

4 Las cifras de pobreza de Belice son menos recientes debido a un problema de disponibilidad de datos que es común en la región, sobre todo en los países del Caribe.

5 En un esfuerzo por comprender la pobreza más allá del aspecto económico y por reconocer que tanto ella como el desarrollo son multidimensionales, el PNUD, en colaboración con la Oxford Poverty and Human Development Initiative (OPHI), publicó su primer índice de pobreza multidimensional (IPM) en el Informe sobre Desarrollo Humano 2010 (PNUD, 2010). Este novedoso indicador complementa la pobreza económica al considerar las privaciones simultáneas que se presentan en tres dimensiones: educación, salud y nivel de vida.

6 Los mapuches son el grupo indígena más numeroso de Chile y representan el 7,5\% de la población total.

7 En el método adaptado para estimar el IPM de los mapuches rurales se tuvieron en cuenta las diferencias relacionadas con las condiciones de vida al no considerar el piso de tierra como una privación y al cambiar el punto de corte relativo a la privación en el acceso al agua.

8 En varios estudios se ha examinado la vulnerabilidad a la pobreza teniendo en cuenta los últimos avances metodológicos y la disponibilidad de datos. En Cruces y otros (2010) se estima la vulnerabilidad a la pobreza en 18 países de América Latina y el Caribe entre principios de la década de 1990 y mediados de la década de 2000. Se utilizan diferentes líneas de pobreza internacionales, y los resultados indican que la tasa de vulnerabilidad es mucho mayor que la pobreza real en América Latina. Aunque la vulnerabilidad agregada de la región ha disminuido con el tiempo, hay grandes diferencias entre los países, y algunos se han quedado totalmente atrás. En Bronfman (2014) se emplean datos de panel de encuestas de hogares para explorar la dinámica de la pobreza en Chile y se revela un alto nivel de vulnerabilidad. En cada uno de los años estudiados (1996, 2001 y 2006), la vulnerabilidad supera de forma considerable las estimaciones de pobreza vigentes.

9 Las personas LGBT se enfrentan a las mismas dificultades socioeconómicas que otras personas de su mismo sexo, raza, origen étnico, edad y condición de discapacidad. Pero también afrontan obstáculos que surgen exclusivamente debido a su orientación sexual e identidad de género. Entre ellos se encuentran el mayor riesgo de quedarse sin hogar en la juventud, el acoso y la discriminación en la escuela y en el lugar de trabajo, y la negación de los beneficios económicos del matrimonio (Sears y Badgett, 2012). 
está altamente expuesta tanto a riesgos idiosincráticos como agregados, lo que resulta preocupante dada la alta prevalencia que los choques climáticos y los desastres naturales tienen en la región. En los últimos 50 años, el número de desastres naturales y la gravedad de estos han aumentado de forma constante en América Latina y el Caribe (Vargas, 2015), sobre todo en esta última subregión. Algunos fenómenos recientes han tenido un costo importante en lo que atañe a las vidas humanas y a la actividad económica, especialmente en los sectores de la agricultura y el turismo. En ausencia de sistemas de protección sólidos y de acceso a mecanismos de mitigación, estos choques pueden volver a empujar a grandes grupos de la población a la pobreza y echar por tierra los logros anteriores.

No obstante, los países han comenzado a reconocer los retos que plantea el medio ambiente. En muchos países de la región el desarrollo se ha basado en la extracción de recursos no renovables - minerales y combustibles fósiles - y yo se ha prestado atención a la sostenibilidad ni a la protección del medio ambiente. Esto ha dado como resultado la degradación de este último, la fragilidad de los ecosistemas y la puesta en peligro de valiosas reservas naturales, lo que alimenta un conflicto socioambiental que afecta de manera desproporcionada a los indígenas que viven en esos territorios (CEPAL y otros, 2018).

Los gobiernos deben reconocer la importancia de los sistemas de protección social como herramienta para alcanzar los ODS. Diseñar y aplicar un piso de protección social para los más pobres y vulnerables se ha convertido en algo esencial, sobre todo en el contexto de la desaceleración económica. Es necesario construir sistemas de protección social sólidos, inclusivos y de amplio alcance que permitan superar estas dificultades, lo que solo se puede lograr si se tienen en cuenta los retos sociales y medioambientales como un aspecto central de la nueva generación de políticas y programas.

\section{Los sistemas de protección social en América Latina y el Caribe: evolución pasada y reciente}

Como ya se ha indicado, los sistemas de protección social constan de tres elementos: asistencia social, seguro social y políticas dirigidas al mercado laboral. Estos elementos tienen por objeto reducir la pobreza y la vulnerabilidad, y en general se financian a partir de las rentas generales. Algunos ejemplos son las transferencias condicionadas y no condicionadas, los subsidios directos, las pensiones no contributivas y los servicios que se prestan de forma gratuita. Los programas de seguro social, por otra parte, proporcionan mecanismos para hacer frente a los choques y ofrecen pensiones contributivas, seguros y servicios pagados tanto estatales como privados (subvencionados). Los sistemas de protección social son multidimensionales y complejos, y a menudo abarcan varios programas y sectores. Se utilizan para hacer frente a la pobreza, tanto crónica como transitoria, y para reducir la vulnerabilidad.

En los sistemas de protección social de los países de América Latina y el Caribe ha habido dos grandes oleadas de reformas. A principios de los años noventa se llevaron a cabo varias reformas de los programas de seguro social, sobre todo de los sistemas de jubilaciones y pensiones de invalidez. Estos programas, todos muy dependientes de la capacidad del gobierno para financiarlos, se habían diseñado en los años veinte y se reformaron a mediados de siglo, basados en las ideas de Bismarck y luego de Beveridge sobre el Estado de bienestar.

La necesidad de ajustarlos surgió tras la crisis de la deuda de los años ochenta. Los grandes déficits generados por los fondos sociales fomentaron la aplicación generalizada de políticas económicas neoliberales en toda la región. En varios países se cambiaron los sistemas de beneficios definidos por sistemas de contribuciones definidas y capitalización individual, mientras que en otros se introdujeron cambios paramétricos para hacer frente a la presión fiscal. En 1981, Chile se convirtió en el primer país en que el sistema regional de reparto se sustituyó por cuentas individuales de ahorro 
para la jubilación. En varios países se siguió el mismo camino en la década de 1990: en algunos - Bolivia (Estado Plurinacional de), El Salvador, México y República Dominicana- se puso en práctica el sistema chileno, mientras que en otros - Argentina, Colombia, Costa Rica, Perú y Uruguay - se combinaron las cuentas privadas con sistemas de reparto de beneficios definidos (véase más información en Barrientos, 2011, y Mesa-Lago, 2008).

La segunda oleada regional de reformas de la protección social tuvo lugar en los primeros años de la década de 2000 y se centró en la asistencia social. En la mayoría de los países de la región se ampliaron los programas de asistencia social reconociendo las diferentes necesidades que surgen durante el ciclo de vida e introduciendo transferencias no contributivas de ingresos dirigidas a las personas en situación de pobreza y vulnerabilidad. En varios países se amplió la pensión no contributiva para reducir la pobreza en las personas de mayor edad: algunos ejemplos son el Programa Especial de Transferencia Económica a los Adultos Mayores (120 a los 65) de Panamá, la Pensión para las Personas de Edad de Trinidad y Tabago, la Pensión Básica Solidaria de Chile y el Beneficio de Prestación Continua (BPC) del Brasil. En los últimos 15 años, en 18 países de América Latina y el Caribe se han introducido reformas similares, lo que ha aumentado la protección de los ingresos de las personas mayores al extender la cobertura más allá de los trabajadores del sector formal (Rofman, Apella y Vezza, 2013).

Además, en varios sistemas se reconoció la importancia del desarrollo en la infancia y la dependencia que los niños tienen respecto de terceros (padres o cuidadores), y también se diseñaron programas que tenían por objeto promover y proteger ese desarrollo. Por ejemplo, en 2009, el programa Chile Crece Contigo permitió que las madres accedieran a atención sanitaria durante el embarazo y ofreció controles de salud periódicos para los niños, desde el nacimiento hasta el comienzo de la etapa escolar. La cobertura se amplió posteriormente hasta la finalización de la educación primaria. Los Ministerios de Educación y Salud también participaron y ofrecieron un conjunto integral de programas de desarrollo infantil. Del mismo modo, la Estrategia Nacional de Desarrollo e Inclusión Social del Perú, "Incluir para Crecer", se centró en cinco áreas diferentes del desarrollo de los niños y los adolescentes con el fin de reducir la malnutrición en la primera infancia, promover el desarrollo físico y emocional, y fomentar las capacidades de los niños mayores. En Bolivia (Estado Plurinacional de), Colombia y Venezuela (República Bolivariana de) se han creado programas similares.

En el cuadro 1 se enumeran varios programas de pensiones no contributivas y sus características. La mayoría de los programas se aplicaron con independencia del sistema existente de pensiones contributivas y estaban dirigidos a personas que anteriormente quedaban excluidas; en otros casos, los sistemas no contributivos recién creados pasaron a formar parte del régimen anterior (por ejemplo, en el Brasil, Chile y el Uruguay).

En estos procesos de reforma también se introdujeron programas de transferencias condicionadas. Tras el pionero programa Progresa de México (más tarde conocido como Oportunidades y ahora como Prospera), que se diseñó y puso en marcha a finales de los años noventa, se han incorporado este tipo de programas en los planes de asistencia social de todos los demás países de América Latina y el Caribe. Aunque estos programas no son contributivos, los beneficiarios tienen que cumplir algunas condiciones para obtener las prestaciones. Los programas de transferencias condicionadas tienen por objeto cambiar el comportamiento de los beneficiarios: se les exige que hagan uso de servicios de salud, nutrición y educación, vinculando así las transferencias de ingresos a la acumulación de capital humano. Este modelo de asistencia social ayuda a los beneficiarios a corto plazo, porque proporciona un apoyo directo a los ingresos de los hogares pobres y vulnerables al mismo tiempo que promueve la acumulación de capital humano. A largo plazo también fomenta el desarrollo y reduce la dependencia. 


\section{Cuadro 1}

América Latina y el Caribe (países seleccionados): programas de pensiones no contributivas, población beneficiaria e integración con el sistema contributivo

\begin{tabular}{|c|c|c|c|}
\hline País & Programa & Población beneficiaria & $\begin{array}{l}\text { Integración con el } \\
\text { sistema contributivo }\end{array}$ \\
\hline Argentina & Programa de Inclusión Previsional & Destinado a lograr la universalidad & Independiente \\
\hline $\begin{array}{l}\text { Bolivia (Estado } \\
\text { Plurinacional de) }\end{array}$ & Renta Dignidad & Universal & Independiente \\
\hline Brasil & $\begin{array}{l}\text { Previdência Rural } \\
\text { Beneficio de Prestación Continua (BPC) }\end{array}$ & $\begin{array}{l}\text { Destinado a lograr la universalidad } \\
\text { Destinado a lograr la universalidad }\end{array}$ & $\begin{array}{l}\text { Integrado } \\
\text { Integrado }\end{array}$ \\
\hline Chile & Pensión Básica Solidaria & Destinado a lograr la universalidad & Integrado \\
\hline Colombia & Colombia Mayor & Destinado a beneficiarios específicos & Independiente \\
\hline Costa Rica & $\begin{array}{l}\text { Régimen no Contributivo de } \\
\text { Pensiones por Monto Básico }\end{array}$ & Destinado a beneficiarios específicos & Independiente \\
\hline Ecuador & Bono de Desarrollo Humano) & Destinado a beneficiarios específicos & Independiente \\
\hline El Salvador & Pensión Básica Universal & Destinado a beneficiarios específicos & Independiente \\
\hline México & "70 y más" & Destinado a lograr la universalidad & Independiente \\
\hline Panamá & $\begin{array}{l}\text { Programa Especial de Transferencia Económica } \\
\text { a los Adultos Mayores (120 a los 65) }\end{array}$ & Destinado a lograr la universalidad & Independiente \\
\hline Paraguay & Pensión Alimentaria para Adultos Mayores & Destinado a beneficiarios específicos & Independiente \\
\hline Perú & $\begin{array}{l}\text { Programa Nacional de Asistencia } \\
\text { Solidaria "Pensión 65" }\end{array}$ & Destinado a beneficiarios específicos & Independiente \\
\hline Uruguay & $\begin{array}{l}\text { Flexibilización del sistema contributivo/ } \\
\text { reforma de la pensión por vejez }\end{array}$ & Destinado a lograr la universalidad & Integrado \\
\hline Trinidad y Tabago & Pensión para las Personas de Edad & Universal & Integrado \\
\hline
\end{tabular}

Fuente: Elaboración propia, sobre la base de R. Rofman, I. Apella y E. Vezza (eds.), Más allá de las pensiones contributivas: catorce experiencias en América Latina, Washington, D.C., Banco Mundial, 2013; y Comisión Económica para América Latina y el Caribe (CEPAL), Base de Datos de Programas de Protección Social No Contributiva en América Latina y el Caribe, 2016 [en línea] https://dds.cepal.org/bpsnc/inicio.

En el cuadro 2 se enumeran los programas de transferencias condicionadas que se aplican en la región, la mayoría de los cuales están dirigidos a las mujeres y los niños y se centran en la asistencia a la escuela y los controles de salud. Sin embargo, las condiciones, la complejidad y la amplitud de los programas varían. En cada país los programas se han adaptado al contexto político e institucional específico, con diferencias en cuanto a las prestaciones, los mecanismos de entrega, la cobertura geográfica y demográfica, los vínculos institucionales y el compromiso presupuestario (Cecchini y Atuesta, 2017). Los últimos datos muestran que la cobertura varía considerablemente de un país a otro. En algunos casos, los programas atienden a más de una cuarta parte de la población (por ejemplo, en el Brasil, el Ecuador, México y la República Dominicana), mientras que en otros cubren a menos del 5\% (como en Belice, Chile, Costa Rica y Haitî). La escasa cobertura podría ser un signo de éxito en el caso de los programas dirigidos a las personas en situación de pobreza extrema, como ocurre en Chile o Costa Rica; no obstante, en otros casos, como Belice o Haití, es un signo de dificultades institucionales o de implementación. En toda la región, la cobertura de las transferencias condicionadas pasó de menos de 300.000 hogares en 1997 a 29,8 millones en 2015 (el 17,5\% de todos los hogares de la región). Sin embargo, los datos muestran un descenso de la participación a partir de 2014, tendencia que es preocupante porque coincide con el aumento de las tasas de pobreza en toda América Latina y el Caribe (Cecchini y Atuesta, 2017). 


\section{Cuadro 2}

América Latina y el Caribe (países seleccionados): programas de transferencias condicionadas

\begin{tabular}{|c|c|c|c|}
\hline País & Programa & Condicionalidad & $\begin{array}{c}\text { Cobertura } \\
\text { (en porcentajes) }\end{array}$ \\
\hline \multirow[t]{4}{*}{ Argentina } & Familias por la Inclusión Social (2005-2010) & E, Sa y So & 7,47 \\
\hline & Asignación Universal por Hijo (AUH) (2009-) & E, Sa y So & 8,04 \\
\hline & Programa de Ciudadanía Porteña (2005-) & E, Sa y Id & 0,38 \\
\hline & Plan Jefas y Jefes de Hogar Desocupados (2002-2005) & E, Sa y C & 5,56 \\
\hline Belice & Creando Oportunidades para Nuestra Transformación Social (B00ST) (2011-) & Ey Sa & 2,65 \\
\hline \multirow{2}{*}{$\begin{array}{l}\text { Bolivia (Estado } \\
\text { Plurinacional de) }\end{array}$} & Bono Juancito Pinto (2006-) & $\mathrm{E}$ & 20,74 \\
\hline & Bono Madre Niño-Niña "Juana Azurduy" (2009-) & Ey Sa & 2,19 \\
\hline \multirow[t]{5}{*}{ Brasil } & Bolsa Escola (2001-2003) & $\mathrm{E}$ & 0,00 \\
\hline & Bolsa Família (2003-) & E, Sa y So & 26,57 \\
\hline & Bolsa Alimentação (2001-2003) & $\mathrm{Sa}$ & 0,00 \\
\hline & Programa de Erradicación del Trabajo Infantil (PETI) (1997-) & Ey So & 0,43 \\
\hline & Bolsa Verde (2011-) & RNS & 0,14 \\
\hline \multirow[t]{2}{*}{ Chile } & Chile Solidario (2002-2012) & Ey Sa & 12,36 \\
\hline & Ingreso Ético Familiar (2012-) & E, Sa y T & 4,08 \\
\hline \multirow[t]{4}{*}{ Colombia } & Familias en Acción & E, Sa y C & 9,21 \\
\hline & Ingreso para la Prosperidad Social & Ey Sa & - \\
\hline & Red Unidos & Ey So & 9,65 \\
\hline & Subsidios Condicionados a la Asistencia Escolar (Bogotá) & $\mathrm{E}$ & 0,10 \\
\hline \multirow[t]{2}{*}{ Costa Rica } & Superémonos (2000-2002) & E & - \\
\hline & Avancemos (2006-) & Ey Sa & 3,15 \\
\hline \multirow[t]{2}{*}{ Ecuador } & Bono de Desarrollo Humano (BDH) (2003-) & Ey Sa & 32,60 \\
\hline & Desnutrición Cero (2011-) & E, Sa y So & - \\
\hline El Salvador & Programa de Apoyo a Comunidades Solidarias en El Salvador (PACSES) (2005-) & E, Sa, C y So & 8,58 \\
\hline \multirow[t]{3}{*}{ Guatemala } & Mi Familia Progresa (MIFAPRO) (2008-2011) & Ey Sa & - \\
\hline & Mi Bono Seguro (2012-) & Ey Sa & 13,02 \\
\hline & Protección y Desarrollo de la Niñez y Adolescencia Trabajadora (2007-2008) & $\mathrm{E}$ & - \\
\hline Haití & Ti Manman Cheri (2012) & E & 4,40 \\
\hline \multirow[t]{4}{*}{ Honduras } & Programa de Asignación Familiar (PRAF) y PRAF I (1990-2009) & Ey Sa & 8,96 \\
\hline & Proyecto PRAF/BID Fase II (1998-2005) & E, Sa y So & - \\
\hline & Proyecto PRAF/BID Fase III (2006-2009) & Ey Sa & - \\
\hline & Bono 10.000 Educación, Salud y Nutrición (2010-) & Ey Sa & 19,97 \\
\hline Jamaica & Programa de Avance mediante la Salud y la Educación (PATH) & Ey Sa & 13,51 \\
\hline \multirow[t]{2}{*}{ México } & Programa de Desarrollo Humano Oportunidades (ex Progresa) (1997-2014) & Ey Sa & 24,90 \\
\hline & Prospera (programa de inclusión social) (2014-) & Ey Sa & 24,65 \\
\hline \multirow[t]{2}{*}{ Nicaragua } & Programa de Atención a Crisis & E, Sa y C & - \\
\hline & Red de Protección Social & E, Sa y C & - \\
\hline \multirow[t]{2}{*}{ Panamá } & Red de Oportunidades & E, Sa y C & 7,62 \\
\hline & Bonos Familiares para la Compra de Alimentos & E, Sa y C & 1,18 \\
\hline \multirow[t]{2}{*}{ Paraguay } & Abrazo & Ey So & 0,11 \\
\hline & Tekoporâ & So & 8,63 \\
\hline Perú & Programa Nacional de Apoyo Directo a los más Pobres (Juntos) & Ey Sa & 10,67 \\
\hline \multirow{2}{*}{$\begin{array}{l}\text { República } \\
\text { Dominicana }\end{array}$} & Solidaridad (2005-2012) & Ey Sa & 29,37 \\
\hline & Progresando con Solidaridad (2012-) & Ey Sa & 31,33 \\
\hline Trinidad y Tabago & Programa de Transferencias Monetarias Condicionadas Focalizadas (TCCTP) & So & 13,19 \\
\hline \multirow[t]{2}{*}{ Uruguay } & Asignaciones familiares & Ey Sa & 14,00 \\
\hline & Plan de Atención Nacional a la Emergencia Social (PANES) & E, Sa y $A C$ & 9,59 \\
\hline
\end{tabular}

Fuente: Comisión Económica para América Latina y el Caribe (CEPAL), Base de Datos de Programas de Protección Social No Contributiva en América Latina y el Caribe, 2016 [en línea] https://dds.cepal.org/bpsnc/inicio.

Nota: E significa educación, Sa significa salud, T significa trabajo, So significa social, Id significa identificación, C significa capacitación, RNS significa recursos naturales y sostenibilidad, y AC significa actividades comunitarias. 
Como se muestra en el cuadro 2, en la mayoría de los programas de transferencias condicionadas, estas se entregan con la condición de que los hogares hagan inversiones en educación y salud. Entre las condiciones educativas se encuentran la matrícula y la asistencia a la escuela y, en algunos casos, mediciones específicas de desempeño (por ejemplo, en Chile, Colombia y Guatemala) ${ }^{10}$. Las condiciones sanitarias incluyen controles periódicos (sobre todo dirigidos a los recién nacidos y los niños), así como la vacunación de los niños pequeños, la atención perinatal de las madres y la asistencia a reuniones de información sanitaria. Algunos programas de transferencias condicionadas se han vuelto más complejos y en ellos se ha ido más allá de la salud y la educación para incorporar condiciones que permiten abordar otras dimensiones de la pobreza y la vulnerabilidad.

En línea con los ODS, los países están reconociendo los vínculos entre la pobreza y el medio ambiente. Sin embargo, solo un programa de transferencias condicionadas fomenta la conservación de los ecosistemas de forma paralela a la mejora de las condiciones de vida de las personas en situación de pobreza. Sobre la base del programa brasileño de asignaciones familiares Bolsa Família, un programa de transferencias condicionadas, el programa Bolsa Verde usa ese tipo de transferencias como incentivo para que las familias beneficiarias que viven en zonas prioritarias en materia de conservación adopten prácticas sostenibles. Este innovador programa fomenta la conservación, promueve la mejora del nivel de vida, aumenta los ingresos de quienes llevan a cabo actividades de conservación y anima a las personas a participar en capacitación medioambiental, social, técnica y profesional. La actividad se supervisa por satélite y mediante visitas periódicas. Dado que más del $50 \%$ de los brasileños que se encuentran en situación de pobreza extrema viven en zonas rurales, este programa representa un paso importante hacia reconocer y compensar a esas comunidades tradicionales y a esos agricultores familiares por los servicios medioambientales que prestan.

En 2016, en la República Dominicana se diseñó e implementó el índice de vulnerabilidad ante choques climáticos (IVACC). Este índice contiene información sobre 2,5 millones de hogares y permite calcular qué zonas y hogares corren mayor riesgo de sufrir los estragos anuales de la temporada de huracanes. Esta información contribuye a evitar pérdidas humanas y materiales y también inspira el diseño y la aplicación de medidas correctivas dirigidas a los sectores más vulnerables. El índice sirve asimismo como una herramienta esencial a la hora de decidir quiénes serán los beneficiarios de diversos programas sociales, al aportar información complementaria sobre la vulnerabilidad y permitir que se comprenda mejor la exposición al riesgo que da lugar a la pobreza multidimensional. El IVACC es el primer índice de este tipo y ayuda a orientar la acción gubernamental de modo de evitar la pérdida de inversión social y optimizar el gasto social. Se ha convertido en la piedra angular del Plan de Prevención, Mitigación y Respuesta (PMR) del país y ha facilitado la coordinación general del sistema de protección social.

Todas estas reformas fueron producto del cambio político y la demanda popular, aunados a una sólida posición fiscal. Explican en gran medida las impresionantes mejoras que se han observado en la región en este período de tiempo. La expansión de los programas vino acompañada de un aumento del gasto público en protección social. Entre 2002 y 2012, el gasto público social per cápita creció a una tasa promedio anual del 7,3\% en todos los países de América Latina y el Caribe, impulsado por los gastos en protección social (PNUD, 2016a).

Sin embargo, esta labor no ha sido suficiente: el aumento de la cobertura de la protección social sigue planteando grandes desafíos en la región. En promedio, en América Latina y el Caribe se cubre apenas al 56\% de la población que supera la edad mínima de jubilación, y en muchos países, como El Salvador, Guatemala, Honduras, el Paraguay, la República Dominicana y otros, la cobertura está muy por debajo de ese nivel. El acceso a los servicios sanitarios también sigue siendo muy desigual

\footnotetext{
${ }^{10}$ Los requisitos de asistencia a la escuela van del $80 \%$ de los días de clase en el Estado Plurinacional de Bolivia al 95\% de estos en Nicaragua. En la mayoría de los países el requisito mínimo se establece en el 85\%.
} 
y depende del tipo de empleo y de la ubicación geográfica. Los grandes segmentos de la población que trabajan en el sector informal o están territorialmente marginados no pueden acceder en absoluto a las prestaciones de la seguridad social.

En el cuadro 3 se muestran las grandes diferencias entre los países en cuanto a la cobertura de la protección social. En países como Chile, México y el Perú, el nivel de cobertura supera el 86\%, mientras que en Honduras la cobertura solo llega al 2,5\%; en un gran grupo de países (Argentina, Belice, Brasil, Colombia y Nicaragua) se cubre a menos de la mitad de la población. También hay brechas importantes en cuanto a la cobertura de la protección social cuando se trata de las mujeres, y aún más cuando se trata de otros grupos vulnerables, como la población LGBTI.

\section{Cuadro 3}

América Latina y el Caribe (países seleccionados): cobertura de la política social, 2015 (En porcentajes)

\begin{tabular}{|c|c|c|c|}
\hline & $\begin{array}{l}\text { Cobertura total de la } \\
\text { protección social y el } \\
\text { mercado de trabajo }\end{array}$ & $\begin{array}{l}\text { Cobertura total de la } \\
\text { asistencia social }\end{array}$ & $\begin{array}{l}\text { Cobertura total del } \\
\text { seguro social }\end{array}$ \\
\hline \multicolumn{4}{|l|}{ América del Sur } \\
\hline Argentina & 41,1 & 16,3 & 29,0 \\
\hline Bolivia (Estado Plurinacional de) & 76,8 & 75,2 & 8,5 \\
\hline Brasil & 46,4 & 19,5 & 28,3 \\
\hline Chile & 88,4 & 74,2 & 44,6 \\
\hline Colombia & 48,9 & 41,7 & 8,9 \\
\hline Ecuador & 74,0 & 68,0 & 10,7 \\
\hline Paraguay & 52,3 & 47,8 & 6,3 \\
\hline Perú & 89,5 & 86,6 & 12,2 \\
\hline Suriname & - & - & - \\
\hline Uruguay & 79,8 & 59,2 & 36,6 \\
\hline \multicolumn{4}{|l|}{ Centroamérica } \\
\hline Belice & 39,3 & 16,2 & 28,1 \\
\hline Costa Rica & 67,3 & 47,5 & 15,0 \\
\hline El Salvador & 60,2 & 56,2 & 5,5 \\
\hline Guatemala & 64,3 & 61,6 & 3,9 \\
\hline Honduras & 2,5 & 50,9 & 49,2 \\
\hline México & 86,7 & 58,9 & 47,0 \\
\hline Nicaragua & 45,7 & 39,7 & 5,6 \\
\hline Panamá & 63,5 & 52,4 & 17,2 \\
\hline \multicolumn{4}{|l|}{ El Caribe } \\
\hline Jamaica & 68,8 & 67,3 & 4,3 \\
\hline República Dominicana & 35,5 & 31,5 & 5,7 \\
\hline
\end{tabular}

Fuente: Banco Mundial, World Development Indicators, 2016 [base de datos en línea] http://data.worldbank.org/datacatalog/ world-development-indicators.

Nota: En los casos en que no se dispone de datos correspondientes a 2015, las cifras indicadas en el cuadro se refieren a los años cercanos.

La gran proporción de personas que viven en la pobreza o son económicamente vulnerables exige que se amplíen los sistemas de protección social. Tomar en cuenta el costo económico y social de la reproducción y el cuidado de las personas a cargo podría contribuir a hacer de la seguridad social un derecho humano universal y a reducir la brecha de género que ha creado el sistema actual. 


\section{El futuro de los sistemas de protección social y los retos que se plantean}

La evolución positiva de los sistemas de protección social en América Latina y el Caribe en los últimos 25 años es en parte responsable del éxito que han alcanzado muchos países de la región en la reducción de la pobreza y la promoción del desarrollo humano. La ampliación de la cobertura de los planes no contributivos y la creación y puesta en marcha de programas de transferencias condicionadas y no condicionadas han tenido un profundo impacto en millones de vidas. Sin embargo, los grandes retos que plantea la nueva agenda para el desarrollo suponen una presión para que en los sistemas de protección social se conciban formas innovadoras de preservar y ampliar los avances en materia de bienestar. Esos retos exigen lograr un progreso multidimensional en un momento en que la mayoría de los países tienen presupuestos ajustados y están sometidos a restricciones financieras. Aunque en América Latina y el Caribe se lograron sortear eficazmente las consecuencias de la crisis financiera de 2008, en varios países sigue existiendo el riesgo de que esos logros se reviertan.

En el Informe Regional sobre Desarrollo Humano para América Latina y el Caribe de 2016 se pone de manifiesto el gran peligro que corre la región en la actualidad. Los sistemas de protección social y las redes de seguridad desempeñan un papel fundamental para garantizar que las personas que se encuentran en riesgo de volver a caer en la pobreza como consecuencia de la contracción económica actual sigan adquiriendo resiliencia y aumentándola frente a los choques externos, tanto naturales como artificiales (PNUD, 2016a).

Con ese fin, y en respuesta a la crisis financiera de 2007-2008, en la Iniciativa del Piso de Protección Social de la Organización Internacional del Trabajo (OIT) se plantea que los pisos de protección social deberían comprender por lo menos las siguientes garantías básicas de seguridad social: niveles mínimos de seguridad del ingreso durante la niñez, la vida activa y la vejez, y un acceso asequible a la atención médica esencial, incluida la atención de la maternidad, que cumpla los criterios de disponibilidad, accesibilidad, aceptabilidad y calidad (OIT, 2012).

Esta iniciativa propone establecer un conjunto de garantías básicas de seguridad social definidas a nivel nacional y aplicadas a lo largo del ciclo de vida de los ciudadanos. Se garantiza que las personas necesitadas tengan acceso a la asistencia sanitaria y gocen de la seguridad de contar con un ingreso básico, y se fomenta el acceso a los bienes y servicios necesarios definidos a nivel nacional. La literatura destaca dos factores principales que indican la necesidad de sistemas más sólidos de protección social en América Latina y el Caribe en la actualidad. El primero es el reconocimiento de la pobreza como un fenómeno multidimensional. El PNUD (2016a) subraya que el bienestar va más allá de los ingresos, y se centra en el progreso multidimensional y en la lucha contra la pobreza multidimensional. De hecho, en el último decenio ha habido importantes avances metodológicos en la medición de este tipo de pobreza (Bourguignon y Chakravarty, 2003; Bossert, Chakravarty y D'Ambrosio, 2009; Alkire y Foster, 2011; Chakravarty y D'Ambrosio, 2013). El trabajo iniciado por la Oxford Poverty and Human Development Initiative (OPHI), que incluye el índice de pobreza multidimensional (IPM), es especialmente pertinente. El IPM, que fue introducido en 2010 por la OPHI y el PNUD, permite hacer un seguimiento interanual del progreso multidimensional en más de 100 países. En varios países de América Latina y el Caribe (por ejemplo, en Chile, Colombia, El Salvador, México, Nicaragua, el Perú y la República Dominicana) se han puesto en práctica o se están diseñando mediciones propias de la pobreza multidimensional. Este nuevo conjunto de mediciones permite comprender mejor la pobreza y la privación, al proporcionar datos sobre diferentes aspectos del bienestar que no se reflejan en los ingresos o el consumo de los hogares. No obstante, se necesita más información sobre los grupos marginados.

Estas nuevas mediciones y estimaciones ejercen una gran presión sobre los programas gubernamentales existentes para que aborden estas múltiples privaciones. Un ejemplo es el programa 
mexicano Prospera. De acuerdo con las mediciones de la pobreza multidimensional correspondientes a 2014, en México 55,3 millones de personas (o un 42\% de los habitantes del país) no tenían acceso a derechos sociales básicos (CONEVAL, 2015). Este índice reveló que la mayor parte de las privaciones se derivaban de la falta de acceso a servicios de seguridad social, alimentación y salud. Ante ese diagnóstico, en el Programa Nacional de Desarrollo Social 2014-2018 se estableció que las transferencias monetarias debían combinarse con otras políticas para crear oportunidades y aumentar la capacidad de combatir la pobreza en México.

El nuevo enfoque llevó a que el programa Progresa, que era un programa de transferencias condicionadas, evolucionara y se convirtiera en Prospera, que es un sistema de inclusión social. El nuevo programa tiene por objeto reforzar la aplicación de los derechos sociales y la creación de capacidades para romper el ciclo intergeneracional de la pobreza. Para lograr este objetivo, Prospera brinda a sus beneficiarios las siguientes prestaciones: apoyo monetario directo para mejorar la calidad y la cantidad de los alimentos; acceso a servicios sanitarios de calidad; más acceso a la educación y a becas que fomentan el rendimiento, y mayor acceso a información sobre alfabetización financiera, formación para el empleo y otros.

El segundo factor que promueve el fortalecimiento de los sistemas de protección social es la mayor exposición al riesgo y el aumento de la vulnerabilidad a la pobreza. Como ya se ha señalado, la mayoría de las personas que han salido de la pobreza siguen viviendo en el límite: cualquier choque idiosincrático o agregado podría volver a empujarlas a una situación de privación. Además, la frecuencia y la gravedad de los desastres naturales recientes, como los huracanes, las erupciones volcánicas y los terremotos, han afectado millones de vidas. Por ejemplo, el terremoto de siete grados de magnitud que arrasó Haití en enero de 2010 se cobró un precio enorme, y los elevados niveles de pobreza, junto con la ausencia de una red sólida de protección social, han impedido que el país se recupere con rapidez. A medida que en Haití se sigue mejorando la infraestructura, también se debe trabajar para construir sistemas más sólidos y resilientes.

El hecho es que, aunque hay varios ejemplos positivos de progreso innovador, los sistemas de protección social de la región tienen graves limitaciones y plantean grandes retos. Es necesario seguir innovando en materia de política social para abordar estas cuestiones y promover un proceso de desarrollo más sostenible e inclusivo. A continuación se destacan los principales retos.

\section{La pobreza, la vulnerabilidad y los grupos excluidos}

Según el PNUD (2016b), más de la mitad de la población de América Latina y el Caribe es pobre o vulnerable a la pobreza, sobre todo si se tienen en cuenta los frecuentes choques ambientales y naturales que se presentan en la región. La mayoría de los programas sociales están dirigidos a los pobres, pero entre los beneficiarios no se incluye a quienes corren riesgo de caer en la pobreza: una vez que las personas salen de la pobreza monetaria, dejan de cumplir los requisitos para recibir asistencia social, y eso crea una importante brecha de protección. Hay una necesidad urgente de ampliar los programas permitiendo la creación de redes de seguridad social para reducir la vulnerabilidad y fomentar la resiliencia.

Al mismo tiempo, la vulnerabilidad y la exclusión del sistema de protección social están relacionadas con las características del mercado laboral y con el tipo de empleo. Gran parte de la población de la región está excluida de la protección social debido al tipo de empleo que desempeña: mientras que los trabajadores asalariados y formales están cubiertos por los sistemas de pensiones y de salud, los trabajadores informales y no asalariados no lo están. Ampliar el acceso a los recursos físicos y financieros, mejorar los sistemas de cuidados y fomentar las habilidades podría dar lugar a mejores mecanismos de resiliencia y a un mayor grado de protección contra los choques para todos. 
Está demostrado que un sistema de protección social sólido ayuda a las personas a salir de la pobreza monetaria y a no caer otra vez en ella; por ejemplo, el aumento de la cobertura de las pensiones en Chile y el Perú parece estar vinculado a una mayor probabilidad de que los hogares salgan de la pobreza económica (PNUD, 2016a).

Varios grupos importantes de la población también están excluidos de los sistemas de protección social existentes debido a la imperfección de los diseños y mecanismos de focalización. La necesidad de ampliar y reformar se justifica no solo por el aumento de la población vulnerable, sino también como medio para integrar a los que históricamente han quedado excluidos del proceso de desarrollo.

En los dos últimos decenios, la participación de las mujeres en el mercado laboral ha aumentado considerablemente y la brecha salarial de género se ha reducido. Sin embargo, las mujeres siguen enfrentando discriminación y dificultades institucionales y culturales, y ganan menos que los hombres por los mismos trabajos. La naturaleza más precaria y menos formal de su trabajo también las hace más vulnerables. Incluso cuando consiguen incorporarse a la población activa formal, se ven excluidas de forma desproporcionada del trabajo a tiempo completo porque cargan con la mayoría de las responsabilidades domésticas y las relacionadas con los hijos. Para detectar las brechas de género y ayudar a cerrarlas hay que empezar por determinar cuál es el costo económico y social de la reproducción y las labores de cuidado. Será crucial establecer un sistema universal de seguridad social en que esto se reconozca y en que las transferencias no estén vinculadas a la participación en el mercado laboral.

Otro segmento importante de la población, la comunidad indígena, también ha sido excluida del proceso de desarrollo y ha tenido un acceso limitado a los programas de protección social. Se la considera muy vulnerable debido a su estilo de vida y al alto grado de discriminación del que es objeto. Como ya se ha señalado, tener un origen étnico o racial indígena o afrodescendiente se asocia con una menor probabilidad de salir de la pobreza. Los sistemas de protección social le han fallado a estas comunidades debido a la distancia o a la falta de coherencia entre la política gubernamental y sus prácticas culturales.

Por ejemplo, la cobertura de la protección social es extremadamente baja entre los indígenas del Estado Plurinacional de Bolivia, aunque más del $40 \%$ de la población del país se autoidentifica como indígena ${ }^{11}$. Un estudio reciente concluyó que gran parte de esta exclusión es resultado de las limitadas oportunidades que este grupo tiene en el mercado laboral (Monterrey Arce, 2013). Además, la mayoría de los indígenas viven en zonas rurales y trabajan la tierra para subsistir, lo que los pone en riesgo de experimentar choques naturales significativos. A la falta de cobertura de los indígenas se suma que en esos grupos hay una mayor incidencia de enfermedades y un menor acceso a los programas públicos de vacunación (Monterrey Arce, 2013), así como un menor nivel de partos atendidos en instituciones médicas formales, lo que aumenta el riesgo de mortalidad materna. Hay brechas similares en los indicadores de educación, entre ellos los niveles de alfabetización, la escolaridad y la asistencia a la escuela.

En Panamá, el 21,5\% de la población tiene raíces indígenas y africanas ${ }^{12}$. Estos grupos tienen menos acceso a la educación, a los servicios de capacitación y a las oportunidades en general, lo que se traduce en mayores niveles de pobreza y vulnerabilidad. En dicho país se han impulsado varias iniciativas para mejorar la cobertura de la protección social de esos grupos; por ejemplo, se han simplificado los sistemas de registro, se han diseñado y utilizado recursos multiculturales destinados a los centros educativos y sanitarios, y se ha mejorado la infraestructura en zonas remotas, medidas que han dado buenos resultados a la hora de promover la reducción de la pobreza y la acumulación de capital humano.

\footnotetext{
${ }^{11}$ Datos del censo de 2012.

12 Datos del censo de 2012.
} 
El programa Prospera de México también ha evolucionado para llegar a la población indígena del país. Cuando se observó que estos grupos tenían un bajo índice de aprovechamiento y dificultades para acceder a los servicios, en el Plan Indígena 2014-2018 se elaboraron materiales de comunicación sobre recursos de salud y educación en varias lenguas, lo que benefició a las comunidades mayas, tzotziles, tarahumaras, tepehuanas, mazahuas, tlapanecas/mephaa, otomíes, huicholas, coras, mixtecas y nahuas. Hacia el futuro se pretende elaborar materiales en otros idiomas. En el plan también se contrató personal que hablaba lenguas indígenas para que recopilara información sobre los hogares, lo que permitió ofrecer orientación y apoyo personalizados a los beneficiarios del programa.

En cuanto a las condiciones de vida de grupos como las personas LGBTI, que son objeto de discriminación, no hay estudios regionales que proporcionen información. Además, son pocos los ejemplos de acciones positivas destinadas a promover la inclusión de estos grupos en los sistemas de protección social.

Adaptar los sistemas de protección social a las necesidades de quienes han estado históricamente excluidos podría tener un impacto profundo en la vida de millones de personas en toda la región. La pregunta es: ¿cómo pueden los gobiernos y los ciudadanos diseñar y aplicar nuevos sistemas que lleguen a los excluidos, por ejemplo, a quienes se encuentran en el último tramo, los más pobres, los más vulnerables y los más rezagados que se mencionan en la Agenda 2030? Comprender las diferencias culturales y ampliar los servicios sociales de modo que lleguen a las zonas remotas podría ser la mejor combinación de medidas para promover el crecimiento inclusivo y la igualdad, y al mismo tiempo preservar el valor de las culturas ancestrales.

\section{Los retos del ciclo de vida: adaptar la protección para abarcar a los niños, los jóvenes, la población en edad de trabajar y las personas mayores}

En el marco del nuevo paradigma de desarrollo que exige lograr un progreso multidimensional y proteger los logros ya alcanzados, es necesario reformar los sistemas de protección social para ofrecer cobertura a los ciudadanos a lo largo de todo el ciclo vital. Estos sistemas deben convertirse en una cadena continua de protección, con diferentes programas que permitan abordar los riesgos a los que se enfrentan las personas en las diferentes etapas de la vida. Los programas deben estar diseñados para cubrir el desarrollo en la primera infancia, los niños en edad escolar, los jóvenes, los adultos en edad de trabajar y las personas mayores. Abordar las vulnerabilidades del ciclo vital evita que las personas acumulen riesgos a lo largo de la vida; por ejemplo, el desarrollo en la primera infancia tiene una repercusión duradera en la productividad y el bienestar de los ciudadanos más adelante en la vida. Aumentar la protección y fomentar la capacidad también ayuda a disminuir la transmisión intergeneracional de la privación y la pobreza.

Los países de América Latina y el Caribe están atravesando una transición demográfica que se caracteriza por el aumento sostenido de la tasa de dependencia de las personas mayores. La disminución de las tasas de natalidad y el aumento de la esperanza de vida ejercen presión sobre los sistemas de protección social, especialmente sobre las jubilaciones y la asistencia sanitaria. Según la División de Población de las Naciones Unidas, se prevé que la mediana de edad de la población, la tasa de dependencia de las personas mayores y la esperanza de vida al nacer aumenten de forma considerable en los próximos decenios (Naciones Unidas, 2019). Hoy las personas en edad de trabajar enfrentan un riesgo importante: pasarán a ser totalmente responsables de los niños y las personas mayores a su cargo, a menos que los países pongan en marcha un sistema robusto que soporte parte de esta carga.

Los programas de protección social deben tomar en cuenta la situación de cada hogar en cuanto a su composición y a los riesgos específicos que enfrenta. La necesidad de hacer este tipo 
de adaptación a medida da lugar a importantes retos relacionados con la información: las reformas deberán ir de la mano del desarrollo de mejores sistemas de datos e información.

En las primeras etapas de la vida, cuando la dependencia es grande y las intervenciones tienen efectos duraderos, los sistemas han de ofrecer programas centrados en la nutrición, la salud, la educación y los cuidados. En el caso de los jóvenes que comienzan su vida laboral, los programas deberían dirigirse a aumentar y garantizar el acceso a empleos y oportunidades que fomenten la independencia y al mismo tiempo apoyen la vida reproductiva. En lo que atañe a los adultos, los sistemas de protección social tendrían que centrarse en la promoción y la protección del empleo y en la generación de ingresos, y al mismo tiempo dotar a los ciudadanos de los mecanismos adecuados para hacer frente a los choques idiosincráticos y agregados. Los programas destinados a las personas mayores deberían orientarse a proteger los ingresos y garantizar el acceso a los servicios asistenciales y de salud, así como a los sistemas de pensiones contributivas y no contributivas.

En resumen, es necesario coordinar mejor las intervenciones públicas y trabajar para ampliar la cobertura de los programas específicos en función de las diferentes prioridades, necesidades y riesgos de los ciudadanos a lo largo de la vida.

\section{La combinación y la articulación de los programas y los sectores}

Para abordar problemas multidimensionales se precisan respuestas multi- e intersectoriales: un enfoque sistémico que permita proteger a los ciudadanos contra la pobreza y el riesgo. En toda América Latina y el Caribe, los sistemas de protección social han evolucionado sin un plan maestro en mente; los programas e instituciones han proliferado sin que hubiera un mandato claro relativo a las prestaciones y los beneficiarios, sobre todo en el caso de los sistemas de salud (Ribe, Robalino y Walker, 2012). Los sistemas fragmentados limitan la movilidad laboral y reducen la productividad, y la falta de coordinación entre los programas hace difícil agrupar los riesgos o aprovechar las economías de escala, lo que aumenta los costos administrativos y de ejecución.

Al reformar el sistema de protección social debería asegurarse la coordinación de los programas y subsistemas aprovechando las posibles sinergias entre las diferentes intervenciones, lo que reduciría la duplicación y la labor global. La creación de una ventanilla única que reúna todos los programas sociales aumentaría la eficiencia general, ampliaría la cobertura y mejoraría la capacidad de respuesta.

El programa Chile Solidario es un buen ejemplo de un esfuerzo por coordinar los programas y ampliar la cantidad de beneficiarios a los que llegan: en otros países se podría aplicar un enfoque similar.

Un elemento que podría facilitar la coordinación sería crear un sistema de información único sobre los beneficiarios que permitiera determinar y satisfacer las necesidades del ciclo de vida en todas las áreas pertinentes para el desarrollo sostenible. Incorporar al diseño del sistema otras dimensiones, como los servicios de los ecosistemas, la resiliencia climática y el apoyo a los ciudadanos para que afronten mejor los desastres naturales, también exige coordinación y mejores fuentes de información. EI IVACC de la República Dominicana es un ejemplo de éxito en este sentido.

Los registros únicos de beneficiarios permiten focalizar las prestaciones de forma más eficiente al reducir el costo de la recolección y la gestión de datos y minimizar los errores de exclusión e inclusión. Por ejemplo, en Chile se ha creado un nuevo sistema para determinar quiénes serán los beneficiarios de los programas sociales. El Registro Social de Hogares, que se puso en marcha a principios de 2016, combina la información del sistema anterior con los datos administrativos obtenidos del seguro de cesantía de Chile, del instituto de seguridad social y de otros ministerios para caracterizar la situación socioeconómica de un hogar - ajustada por el número de dependientes - y el derecho a recibir diversas prestaciones. 
La combinación del alto grado de vulnerabilidad con la inestabilidad de los mercados laborales, los desastres naturales y la necesidad de fomentar el desarrollo sostenible exige niveles mucho más altos de coordinación a la hora de diseñar los programas. Coordinar las intervenciones de los distintos ministerios, sectores y niveles de gobierno es difícil, pero no imposible.

\section{Las restricciones fiscales y los programas universales frente a la focalización}

Las anteriores oleadas de reformas de la asistencia social tuvieron lugar durante un período de bonanza económica. Ahora que el espacio fiscal es más acotado se necesitan formas innovadoras de encarar la protección social que permitan abordar las vulnerabilidades y tener en cuenta las restricciones financieras que experimentan en los países. Por lo tanto, otro reto importante es cómo mejorar la protección social en un marco de responsabilidad fiscal. En la nueva generación de reformas basadas en los derechos sociales se deben resolver los problemas de diseño y coordinación, y al mismo tiempo aumentar la capacidad fiscal para sostenerlas. Esto exige no solo recursos, sino también un cambio de mentalidad. Pasar de programas dirigidos a grupos específicos a programas universales no es fácil, sobre todo si se tienen en cuenta la escasez de recursos y las diversas necesidades que compiten por ellos. Cuando los recursos fiscales son limitados, las decisiones sobre el gasto social y el rol del Estado recaen en el pueblo. Para legitimar un sistema de protección social es necesario establecer las prioridades mediante un debate democrático y participativo.

Para lograr estos resultados se necesita un nuevo pacto fiscal, en especial si se tiene en cuenta la nueva situación económica regional. Para abordar los retos que plantea la Agenda 2030 se debe modificar la estructura tributaria a fin de aumentar los ingresos públicos procedentes de los impuestos directos, en contraposición con los sistemas de impuestos indirectos y regresivos que rigen en la actualidad, por ejemplo, los impuestos sobre el valor agregado o sobre las ventas, que a menudo anulan por completo los beneficios de las transferencias sociales (PNUD, 2016a).

La necesidad de contar con recursos de protección social también representa una oportunidad para revisar y reformar los sistemas tributarios existentes. Se necesitan nuevos contratos sociales y acuerdos políticos que permitan aumentar los ingresos fiscales y al mismo tiempo mantener los incentivos que promueven el crecimiento económico y el desarrollo del sector privado. En algunos países es preciso reformar la administración del sistema tributario, disminuyendo el número de deducciones y exenciones y eliminando los vacíos legales; en otros países se debería aumentar la tasa de los impuestos o ampliar la base impositiva a fin de garantizar los ingresos para cubrir la creciente demanda de prestaciones no contributivas.

Cada país debe adaptar la reforma fiscal a sus propias circunstancias, fortalezas y debilidades, para lo que se debe alcanzar un consenso social duradero sobre el financiamiento necesario para implementar sistemas de protección social más sólidos y de cobertura más amplia.

\section{Los cambios tecnológicos y el mercado de trabajo}

El debate en torno al cambio tecnológico y a sus efectos en el mercado laboral ha dado lugar a una gran polarización. Una de las visiones considera que la innovación es una amenaza inminente que modificará o sustituirá la mayoría de los puestos de trabajo mediante la introducción de la inteligencia artificial y la automatización. Pocos países están preparados para afrontar un cambio tan rápido y perturbador, y el progreso tecnológico y el aumento de la prima de calificación asociado a él han contribuido a la desigualdad tanto en los países avanzados como en los emergentes (Dabla-Norris y otros, 2015). Desde otro punto de vista se destacan los beneficios que el cambio 
tecnológico puede aportar, ya que el incremento de la productividad y la calidad puede ofrecer la oportunidad de incidir de forma positiva en la calidad de vida.

Sobre la base de estudios de caso que se llevaron a cabo en cinco países asiáticos, Chang y Huynh (2016) concluyen que los sectores que tienen más probabilidades de ser automatizados son la hotelería, el comercio mayorista y minorista, la construcción y la industria manufacturera; en cambio, la automatización es menos probable en la educación y la capacitación, la asistencia sanitaria y el trabajo social. El estudio sugiere que el riesgo de automatización es mayor en los sectores en que se llevan a cabo tareas repetitivas y codificables, y que es menor en los que suponen tareas abstractas, intuitivas o creativas destinadas a resolver problemas. Los autores también muestran que las mujeres y las personas con menos formación tienen más probabilidades de desempeñar trabajos en que el riesgo de automatización es alto, por lo que son muy vulnerables. Esto ocurre sobre todo en América Latina y el Caribe, donde el autoempleo, el trabajo informal y los puestos de trabajo en sectores que exigen poca calificación o que ofrecen salarios bajos pueden marginar a los trabajadores y desalentar el crecimiento tecnológico.

El cambio tecnológico seguramente perturbará los sistemas y las políticas existentes. En los programas sociales y las políticas públicas se deben incorporar programas de fomento de la capacidad que permitan mantenerse al día de los avances y hacer frente a los inminentes cambios. Será de especial importancia dirigir estos esfuerzos a los trabajadores poco calificados y a las mujeres (Chang, Rynhart y Huyn, 2016).

\section{Conclusión y preguntas para profundizar el debate}

América Latina y el Caribe es la región donde más países han alcanzado la mayoría de las metas de los Objetivos de Desarrollo del Milenio. De conformidad con la Agenda 2030 para el Desarrollo Sostenible, en el período posterior a 2015 es necesario que los países reconozcan la pobreza como un fenómeno multidimensional y que aborden su reducción de manera sostenible. Esto exige disminuir las brechas que existen en materia de protección, creando programas destinados a las personas marginadas, vulnerables y en situación de pobreza.

Los sistemas de protección social deben ir más allá de la lucha contra las privaciones actuales y tener en cuenta los riesgos ambientales y sociales, entre ellos la exclusión debida a la discriminación. Un piso mínimo de servicios que se prolongue a lo largo del ciclo de vida del ciudadano puede romper el círculo vicioso de la pobreza y contribuir a que los países alcancen un mayor nivel de desarrollo multidimensional. En este nuevo enfoque también se debe proteger a los ciudadanos de los choques idiosincráticos y agregados que surgen en las diferentes etapas de la vida.

Sobre la base de los principios de justicia social, la Iniciativa del Piso de Protección Social podría elevar el nivel de vida y salvaguardar los logros del pasado. El piso de protección social abarca un amplio abanico de iniciativas, como programas que tienen en cuenta la edad y el género, asignaciones destinadas al cuidado de la familia, apoyo a la seguridad alimentaria, acceso a la salud y al saneamiento, programas relacionados con el mercado laboral y otros.

En los dos últimos decenios, en América Latina y el Caribe se ha hecho mucho por aumentar la cobertura de la protección social. Sin embargo, hacer más de lo mismo no será suficiente para alcanzar las metas de los ODS o preservar los logros ya obtenidos en materia de desarrollo. La nueva agenda para el desarrollo ofrece la oportunidad de que los países reformen los sistemas de protección social y aborden varias metas de forma simultánea. En el marco de los ODS se reconoce la importancia de la protección social, tanto en sí misma como en su calidad de vehículo para 
alcanzar otros objetivos ${ }^{13}$. Al prepararse para ponerla en práctica, los Gobiernos de América Latina y el Caribe deben considerar formas innovadoras para preservar los logros del pasado e incluir a quienes han sido excluidos.

En este ámbito quedan varias preguntas por resolver: i) ¿por dónde se deberían empezar a cambiar los actuales sistemas de protección social de los países?; ii) ¿cómo pueden los gobiernos y los ciudadanos decidir qué dimensiones considerar aparte de la pobreza monetaria?; iii) ¿cómo se pueden financiar programas de protección social básica en los países de renta baja y planificar su expansión a medida que la situación fiscal del país mejore?; iv) ¿cómo pueden los ciudadanos y los funcionarios crear coaliciones para promover reformas de los sistemas de protección social que conduzcan a la universalidad y a la obtención de un piso mínimo?; v) ¿cuáles son los desafíos en materia de coordinación y qué repercusiones institucionales tienen en estos países?, y vi) ¿cómo se puede reducir la brecha de género en los países para mantener a las mujeres fuera de la pobreza en todas sus dimensiones?

\section{Bibliografía}

Alkire, S. y J. Foster (2011), "Counting and multidimensional poverty measurement", Journal of Public Economics, vol. 95, № 7-8, agosto.

Barrientos, A. (2011), "On the distributional implications of social protection reforms in Latin America", WIDER Working Paper, № 2011/069, Helsinki, Instituto Mundial de Investigaciones de Economía del Desarrollo (UNU-WIDER).

Bossert, W., S. Chakravarty y C. D'Ambrosio (2009), "Multidimensional poverty and material deprivation", Working Paper Series, № 2000-129, Society for the Study of Economic Inequality (ECINEQ).

Bourguignon, F. y S. Chakravarty (2003), "The measurement of multidimensional poverty", The Journal of Economic Inequality, vol. 1, abril.

Bronfman, J. (2014), Essays on vulnerability, poverty and social policies: the case of Chile, Washington, D.C., American University.

Bronfman, J. y M. Hadad (2018), "Life versus Mogen: are the Mapuche people living a different life?" [en línea] https://www.sociedadpoliticaspublicas.cl/archivos/noveno/Social_Bronfman_Javier.pdf.

Cecchini, S. y B. Atuesta (2017), "Programas de transferencias condicionadas en América Latina y el Caribe: tendencias de cobertura e inversión", serie Políticas Sociales, № 224 (LC/TS.2017/40), Santiago, Comisión Económica para América Latina y el Caribe (CEPAL).

Cecchini, S., F. Filgueira y C. Robles (2014), "Sistemas de protección social en América Latina y el Caribe: una perspectiva comparada”, serie Políticas Sociales, № 202 (LC/L.3856), Santiago, Comisión Económica para América Latina y el Caribe (CEPAL).

CEPAL (Comisión Económica para América Latina y el Caribe) (2016), La matriz de la desigualdad social en América Latina (LC/G.2690(MDS.1/2)), Santiago.

CEPAL (Comisión Económica para América Latina y el Caribe) y otros (2018), "Promoting equality: an interregional perspective", Documentos de Proyectos (LC/TS.2018/50/Rev.1), Santiago.

Chakravarty, S. y C. D’Ambrosio (2013), "A family of unit consistent multidimensional poverty indices", Poverty and Social Exclusion around the Mediterranean Sea, V. Berenger y F. Bresson (eds.), Nueva York, Springer.

Chang, J. H. y P. Huynh (2016), ASEAN in Transformation: The Future of Jobs at Risk of Automation, Ginebra, Organización Internacional del Trabajo (OIT).

Chang, J. H., G. Rynhart y P. Huynh (2016), ASEAN in Transformation: How Technology is Changing Jobs and Enterprises, Ginebra, Organización Internacional del Trabajo (OIT).

CONEVAL (Consejo Nacional de Evaluación de la Política de Desarrollo Social) (2015), "Multidimensional poverty in Mexico", presentación en el Taller Técnico sobre Pobreza Multidimensional, Brasilia, 25 a 26 de agosto.

\footnotetext{
${ }^{13}$ Véase la lista completa de los 17 ODS en el cuadro A1.2 del anexo.
} 
Cruces, G. y otros (2010), "Vulnerability to poverty in Latin America: empirical evidence from cross-sectional data and robustness analysis with panel data", Working Paper, N 170, Centro de Investigación de la Pobreza Crónica (CPRC).

Dabla-Norris, E. y otros (2015), "Causes and consequences of income inequality: a global perspective", IMF Staff Discussion Note, N 15/13, Washington, D.C., Fondo Monetario Internacional (FMI).

Gobierno de Belice/CARIBANK (Banco de Desarrollo del Caribe) (2010), Country Poverty Assessment Final Report, vol. 1, Londres, Halcrow Group Limited.

López-Calva, L. y otros (2014), "Clases medias y vulnerabilidad a la pobreza: reflexiones desde América Latina”, El Trimestre Económico, vol. 81, №322, abril-junio.

Mesa-Lago, C. (2008), Reassembling Social Security: A Survey of Pensions and Health Care Reforms in Latin America, Oxford, Oxford University Press.

Monterrey Arce, J. (2013), "Sistemas de protección social en América Latina y el Caribe: Estado Plurinacional de Bolivia”, Documentos de Proyectos (LCM.553), Santiago, Comisión Económica para América Latina y el Caribe (CEPAL).

Naciones Unidas (2019), "Data Query”, World Population Prospects [en línea] https://population.un.org/ wpp/DataQuery/. (2015), Objetivos de Desarrollo del Milenio: Informe de 2015, Nueva York.

OIT (Organización Internacional del Trabajo) (2012), Seguridad social para todos: establecimiento de pisos de protección social y de sistemas integrales de seguridad social, Ginebra.

ONUSIDA (Programa Conjunto de las Naciones Unidas sobre el VIH/Sida) (2016), Prevention Gap Report, Ginebra.

PNUD (Programa de las Naciones Unidas para el Desarrollo) (2016a), Progreso multidimensional: bienestar más allá del ingreso. Informe Regional sobre Desarrollo Humano para América Latina y el Caribe, Nueva York. (2016b), Informe sobre Desarrollo Humano 2016: desarrollo humano para todas las personas, Nueva York. (2016c), Leaving No One Behind: A Social Protection Primer for Practitioners, Nueva York.

(2010), Informe sobre Desarrollo Humano 2010. La verdadera riqueza de las naciones: caminos al desarrollo humano, Nueva York.

Rachid, M. y F. Massenzio (2014), Informe sobre el acceso a los derechos económicos, sociales y culturales de la población trans en Latinoamérica y el Caribe, Red Latinoamericana y del Caribe de Personas Trans (REDLACTRANS) [en línea] https://www.plataformalac.org/2016/05/informe-sobre-el-acceso-alos-derechos-economicos-sociales-y-culturales-de-la-poblacion-trans-en-america-latina-y-el-caribe/.

Ribe, H., D. Robalino e I. Walker (2012), De los derechos a la realidad: incentivos, mercados de trabajo, y el desafío de la protección social universal en América Latina y el Caribe, Washington, D.C., Banco Mundial.

Rofman, R., I. Apella y E. Vezza (eds.) (2013), Más allá de las pensiones contributivas: catorce experiencias en América Latina, Buenos Aires, Banco Mundial.

Sears, B. y L. Badgett (2012), "Beyond stereotypes: poverty in the LGBT community", Momentum, № 4.

Vargas, L. H. (2015), "Los retos de los sistemas de protección social en América Latina y el Caribe ante los desastres", Instrumentos de protección social: caminos latinoamericanos hacia la universalización, Libros de la CEPAL, No 136 (LC/G.2644-P), S. Cecchini y otros (eds.), Santiago, Comisión Económica para América Latina y el Caribe (CEPAL). 


\section{Anexo A1}

\section{Cuadro A1.1}

Definiciones de "protección social" de organismos y organizaciones internacionales

\begin{tabular}{|c|c|c|}
\hline Organismo & Definición & Fuente \\
\hline $\begin{array}{l}\text { Organización } \\
\text { Internacional del } \\
\text { Trabajo (OIT) }\end{array}$ & $\begin{array}{l}\text { "En este informe, se hace alusión a la 'protección social' tanto } \\
\text { como una expresión alternativa para 'seguridad social' como } \\
\text { para indicar la protección proporcionada por la seguridad } \\
\text { social en caso de riesgos y necesidades sociales". } \\
\text { "La noción de seguridad social adoptada aquí abarca todas las } \\
\text { medidas que prevean prestaciones, ya sea monetarias o en especie, } \\
\text { para garantizar la protección, entre otras cosas, a partir de } \\
\text { - La falta de ingresos relacionados con el trabajo (o ingresos } \\
\text { insuficientes) causada por enfermedad, invalidez, maternidad, } \\
\text { accidentes del trabajo, desempleo, vejez o muerte de un familiar; } \\
\text { - La falta de acceso (asequible) a servicios de atención de salud; } \\
\text { - El apoyo familiar insuficiente, especialmente } \\
\text { para los niños y adultos dependientes; } \\
\text { - La pobreza generalizada y la exclusión social". }\end{array}$ & $\begin{array}{l}\text { OIT, Informe Mundial sobre la Protección } \\
\text { Social 2014/15: hacia la recuperación } \\
\text { económica, el desarrollo inclusivo y } \\
\text { la justicia social, Ginebra, } 2017 .\end{array}$ \\
\hline Banco Mundial & $\begin{array}{l}\text { Sistemas, políticas y programas que ayudan a las personas y } \\
\text { a las sociedades a afrontar el riesgo y la volatilidad, y que las } \\
\text { protegen de la pobreza y la indigencia, mediante instrumentos } \\
\text { que aumentan la resiliencia, la equidad y las oportunidades. }\end{array}$ & $\begin{array}{l}\text { Banco Mundial, Resilience, Equity, and } \\
\text { Opportunity: The World Bank's Social } \\
\text { Protection and Labor Strategy 2012- } \\
\text { 2022, Washington, D.C., 2012. }\end{array}$ \\
\hline $\begin{array}{l}\text { Fondo de las Naciones } \\
\text { Unidas para la } \\
\text { Infancia (UNICEF) }\end{array}$ & $\begin{array}{l}\text { El conjunto de políticas y programas públicos y privados } \\
\text { destinados a prevenir, reducir y eliminar las vulnerabilidades } \\
\text { económicas y sociales ante la pobreza y la privación. }\end{array}$ & $\begin{array}{l}\text { UNICEF, Integrated Social Protection } \\
\text { Systems: Enhancing Equity for } \\
\text { Children, Nueva York, } 2012 .\end{array}$ \\
\hline $\begin{array}{l}\text { Institute of } \\
\text { Development } \\
\text { Studies (IDS) }\end{array}$ & $\begin{array}{l}\text { Todas las iniciativas públicas y privadas que proporcionan } \\
\text { transferencias de ingresos o de consumo a las personas en } \\
\text { situación de pobreza, protegen a los vulnerables contra los riesgos } \\
\text { asociados a los medios de subsistencia, y mejoran la condición } \\
\text { social y los derechos de los marginados, con el objetivo general } \\
\text { de reducir la vulnerabilidad económica y social de los grupos de } \\
\text { personas en situación de pobreza, vulnerabilidad y marginación. }\end{array}$ & $\begin{array}{l}\text { S. Devereux y R. Sabates-Wheeler, } \\
\text { "Transformative social protection", IDS } \\
\text { Working Paper, No 232, Brighton, Institute } \\
\text { of Development Studies (IDS), } 2004 .\end{array}$ \\
\hline $\begin{array}{l}\text { Banco Asiático de } \\
\text { Desarrollo (BAsD) }\end{array}$ & $\begin{array}{l}\text { Conjunto de políticas y programas diseñados para reducir la pobreza } \\
\text { y la vulnerabilidad promoviendo la eficiencia de los mercados } \\
\text { laborales, disminuyendo la exposición de las personas a los riesgos, } \\
\text { y fomentando la capacidad de estas para protegerse contra los } \\
\text { peligros y la interrupción de los ingresos o la pérdida de estos. }\end{array}$ & $\begin{array}{l}\text { BAsD, "Social Protection", } 2003 \text { [en } \\
\text { línea] https://www.adb.org/sites/default/ } \\
\text { files/institutional-document/32100/ } \\
\text { social-protection.pdf.. }\end{array}$ \\
\hline Unión Europea & $\begin{array}{l}\text { "....un conjunto específico de acciones para mitigar la } \\
\text { vulnerabilidad de la vida de las personas mediante la seguridad } \\
\text { social, ofreciendo protección contra los riesgos y las adversidades } \\
\text { de la vida; mediante la asistencia social, ofreciendo pagos y } \\
\text { transferencias en especie para apoyar y ayudar a los más pobres; } \\
\text { y mediante esfuerzos de inclusión, para mejorar el acceso de } \\
\text { los marginados a la asistencia y la seguridad social”. }\end{array}$ & $\begin{array}{l}\text { Centro de Estudios Avanzados Robert } \\
\text { Schuman, Informe Europeo sobre el } \\
\text { Desarrollo de 2010. La protección social } \\
\text { para el desarrollo inclusivo: una nueva } \\
\text { perspectiva en la cooperación de la UE con } \\
\text { Árica, Unión Europea, Bruselas, } 2010 .\end{array}$ \\
\hline $\begin{array}{l}\text { Programa Conjunto } \\
\text { de las Naciones } \\
\text { Unidas sobre el VIH/ } \\
\text { Sida (ONUSIDA) }\end{array}$ & $\begin{array}{l}\text { El objetivo de la protección social es, en términos generales, reducir } \\
\text { la vulnerabilidad económica y social de todas las personas, y mejorar } \\
\text { la condición social y los derechos de quienes se encuentran en } \\
\text { situación de pobreza y marginación, proporcionando transferencias } \\
\text { sociales y garantizando el acceso a servicios esenciales básicos y a } \\
\text { una regulación equitativa, lo que puede adoptar muchas formas. }\end{array}$ & $\begin{array}{l}\text { M. Temin, HIV-Sensitive Social Protection: } \\
\text { What Does The Evidence Say?, Programa } \\
\text { Conjunto de las Naciones Unidas sobre } \\
\text { el VIH/Sida (ONUSIDA), Ginebra, } 2010 .\end{array}$ \\
\hline
\end{tabular}

Fuente: Programa de las Naciones Unidas para el Desarrollo (PNUD), Leaving No One Behind: A Social Protection Primer for Practitioners, Nueva York, 2016. 
Cuadro A1.2

Objetivos de Desarrollo Sostenible

\begin{tabular}{ll}
\hline & \multicolumn{1}{c}{ 17 Objetivos de Desarrollo Sostenible } \\
\hline Objetivo 1 & Poner fin a la pobreza en todas sus formas y en todo el mundo \\
\hline Objetivo 2 & Poner fin al hambre, lograr la seguridad alimentaria y la mejora de la nutrición y promover la agricultura sostenible \\
\hline Objetivo 3 & Garantizar una vida sana y promover el bienestar de todos a todas las edades \\
\hline Objetivo 4 & Garantizar una educación inclusiva y equitativa de calidad y promover oportunidades de aprendizaje permanente para todos \\
\hline Objetivo 5 & Lograr la igualdad de género y empoderar a todas las mujeres y las niñas \\
\hline Objetivo 6 & Garantizar la disponibilidad y la gestión sostenible del agua y el saneamiento para todos \\
\hline Objetivo 7 & Garantizar el acceso a una energía asequible, fiable, sostenible y moderna para todos \\
\hline Objetivo 8 & Promover el crecimiento económico sostenido, inclusivo y sostenible, el \\
\hline Objetivo 9 & empleo pleno y productivo y el trabajo decente para todos \\
\hline Objetivo 10 & Reducir la desigualdad en los países y entre ellos \\
\hline Objetivo 11 & Lograr que las ciudades y los asentamientos humanos sean inclusivos, seguros, resilientes y sostenibles \\
\hline Objetivo 12 & Garantizar modalidades de consumo y producción sostenibles \\
\hline Objetivo 13 & Adoptar medidas urgentes para combatir el cambio climático y sus efectos \\
\hline Objetivo 14 & Conservar y utilizar sosteniblemente los océanos, los mares y los recursos marinos para el desarrollo sostenible \\
\hline Objetivo 15 & $\begin{array}{l}\text { Proteger, restablecer y promover el uso sostenible de los ecosistemas terrestres, gestionar sosteniblemente los bosques, } \\
\text { luchar contra la desertificación, detener e invertir la degradación de las tierras y detener la pérdida de biodiversidad }\end{array}$ \\
\hline Objetivo 16 & $\begin{array}{l}\text { Promover sociedades pacíficas e inclusivas para el desarrollo sostenible, facilitar el acceso a la justicia } \\
\text { para todos y construir a todos los niveles instituciones eficaces e inclusivas que rindan cuentas }\end{array}$ \\
\hline Objetivo 17 & Fortalecer los medios de implementación y revitalizar la Alianza Mundial para el Desarrollo Sostenible \\
\hline
\end{tabular}

Fuente: Naciones Unidas, Transformar nuestro mundo: la Agenda 2030 para el Desarrollo Sostenible (A/RES/70/1), Nueva York, 2015. 


\section{Cuadro A1.3}

América Latina y el Caribe: indicadores relacionados con la salud, alrededor de 1990, 2000 y 2015

\begin{tabular}{|c|c|c|c|c|c|c|c|c|c|c|c|c|}
\hline & \multicolumn{3}{|c|}{$\begin{array}{l}\text { Mortalidad infantil en } \\
\text { menores de } 1 \text { año } \\
\text { (por cada } 1000 \\
\text { nacidos vivos) }\end{array}$} & \multicolumn{3}{|c|}{$\begin{array}{l}\text { Mortalidad infantil en } \\
\text { menores de } 5 \text { años } \\
\text { (por cada } 1000 \\
\text { nacidos vivos) }\end{array}$} & \multicolumn{3}{|c|}{$\begin{array}{c}\text { Mortalidad materna } \\
\text { (por cada } 100000 \\
\text { nacidos vivos) }\end{array}$} & \multicolumn{3}{|c|}{$\begin{array}{l}\text { Prevalencia de la } \\
\text { subalimentación } \\
\text { en la población } \\
\text { (en porcentajes) }\end{array}$} \\
\hline & 1990 & 2000 & 2015 & 1990 & 2000 & 2015 & 1990 & 2000 & 2015 & 1990 & 2000 & 2015 \\
\hline \multicolumn{13}{|l|}{ América del Sur } \\
\hline Argentina & 24,4 & 18 & 11,1 & 27,6 & 20,2 & 12,5 & 72 & 60 & 52 & 5 & 5 & 5 \\
\hline Bolivia (Estado Plurinacional de) & 85,6 & 58,8 & 30,6 & 124,4 & 80,2 & 38,4 & 425 & 334 & 206 & 38 & 34,6 & 15,9 \\
\hline Brasil & 50,9 & 28,1 & 14,6 & 60,8 & 32 & 16,4 & 104 & 66 & 44 & 14,8 & 12,3 & 5 \\
\hline Chile & 16 & 9,2 & 7 & 19,1 & 10,9 & 8,1 & 57 & 31 & 22 & 9 & 5 & 5 \\
\hline Colombia & 28,9 & 21,2 & 13,6 & 35,1 & 25,1 & 15,9 & 118 & 97 & 64 & 14,6 & 9,9 & 8,8 \\
\hline Ecuador & 44,2 & 28,4 & 21,6 & 56,9 & 34,4 & 64 & 185 & 103 & 22,5 & 19,4 & 17,8 & 10,9 \\
\hline Guyana & 46,6 & 37,2 & 32 & 60,4 & 46,7 & 39,4 & 171 & 210 & 229 & 22,8 & 10,4 & 10,6 \\
\hline Paraguay & 37,1 & 27,7 & 17,5 & 46,5 & 33,5 & 20,5 & 150 & 158 & 132 & 19,5 & 13,3 & 10,4 \\
\hline Perú & 56,3 & 29,6 & 13,1 & 79,7 & 38,6 & 16,9 & 251 & 140 & 68 & 31,6 & 21,6 & 7,5 \\
\hline Suriname & 40,7 & 30,2 & 19 & 47,6 & 34,4 & 21,3 & 127 & 259 & 155 & 15,5 & 14,1 & 8,3 \\
\hline Uruguay & 20,3 & 14,6 & 8,7 & 23,1 & 16,8 & 10,1 & 37 & 31 & 15 & 8,6 & 5 & 5 \\
\hline $\begin{array}{l}\text { Venezuela (República } \\
\text { Bolivariana de) }\end{array}$ & 24,7 & 18,5 & 12,9 & 29,6 & 21,7 & 14,9 & 94 & 90 & 95 & 14,1 & 16,6 & 5 \\
\hline \multicolumn{13}{|l|}{ Centroamérica } \\
\hline Belice & 32,2 & 21,1 & 14,2 & 39,6 & 25 & 16,5 & 54 & 53 & 28 & 9,7 & 6,5 & 6,2 \\
\hline Costa Rica & 14,3 & 11,2 & 8,5 & 16,9 & 13 & 9,7 & 43 & 38 & 25 & 5,2 & 5,2 & 5 \\
\hline El Salvador & 45,9 & 26,8 & 14,4 & 59,4 & 32,4 & 16,8 & 157 & 84 & 54 & 16,2 & 12,5 & 12,4 \\
\hline Guatemala & 59,8 & 39,9 & 24,3 & 80,9 & 50,6 & 29,1 & 205 & 178 & 88 & 14,9 & 22,1 & 15,6 \\
\hline Honduras & 45,1 & 30,5 & 17,4 & 58,2 & 37,4 & 20,4 & 272 & 133 & 129 & 23 & 19 & 12,3 \\
\hline México & 37,1 & 21,6 & 11,3 & 46,6 & 25,6 & 13,2 & 90 & 77 & 38 & 6,9 & 5 & 5 \\
\hline Nicaragua & 50,9 & 32,6 & 18,8 & 66,9 & 40,3 & 22,1 & 173 & 202 & 150 & 54,4 & 34,8 & 16,6 \\
\hline Panamá & 25,7 & 21,9 & 14,6 & 30,9 & 26 & 17 & 102 & 82 & 94 & 26,4 & 27,4 & 10 \\
\hline \multicolumn{13}{|l|}{ El Caribe } \\
\hline Antigua y Barbuda & 24 & 13,8 & 5,8 & 25,5 & 15,5 & 8,1 & - & - & - & - & - & - \\
\hline Bahamas & 19,7 & 13,2 & 9,9 & 23,5 & 15,7 & 12,1 & 46 & 61 & 80 & - & - & - \\
\hline Barbados & 16 & 14,8 & 12 & 17,9 & 16,3 & 13 & 58 & 48 & 27 & 5 & 5 & 5 \\
\hline Cuba & 10,6 & 6,5 & 6,5 & 13,3 & 8,4 & 8,4 & 58 & 43 & 43 & 5,7 & 5,6 & 5 \\
\hline Dominica & 14,2 & 13,4 & 19,6 & 17,1 & 15,3 & 21,2 & - & - & - & - & - & - \\
\hline Granada & 18 & 13,6 & 10,8 & 23,3 & 16 & 11,8 & 41 & 29 & 27 & - & - & - \\
\hline Haití & 101 & 75 & 52,2 & 145,8 & 104,8 & 69 & 625 & 505 & 359 & 61,1 & 55,2 & 53,4 \\
\hline Jamaica & 25,4 & 19,3 & 13,5 & 30,6 & 22,7 & 15,7 & 79 & 88 & 89 & 10,4 & 7,8 & 8,1 \\
\hline Puerto Rico & - & - & - & - & - & - & 26 & 22 & 14 & - & - & - \\
\hline República Dominicana & 46,5 & 33,3 & 25,7 & 60,2 & 41,3 & 30,9 & 198 & 79 & 92 & 34,3 & 30,7 & 12,5 \\
\hline Saint Kitts y Nevis & 23,1 & 15 & 8,4 & 28,4 & 18,6 & 10,5 & - & - & - & - & - & - \\
\hline San Vicente y las Granadinas & 20,3 & 19,2 & 16,6 & 24,5 & 22,2 & 18,3 & 58 & 74 & 45 & 20,7 & 18,9 & 6,2 \\
\hline Santa Lucía & 18,7 & 15,2 & 12,7 & 22,6 & 17,8 & 14,3 & 45 & 54 & 48 & - & - & - \\
\hline Trinidad y Tabago & 26,9 & 25,3 & 18,2 & 30,5 & 28,7 & 20,4 & 90 & 62 & 63 & 12,6 & 13 & 8 \\
\hline
\end{tabular}

Fuente: Banco Mundial, World Development Indicators, 2016 [base de datos en línea] http://data.worldbank.org/datacatalog/ world-development-indicators.

Nota: En los casos en que no se dispone de datos correspondientes al año exacto, las cifras indicadas en el cuadro se refieren a los años cercanos. En varios países del Caribe no se dispone de datos sobre las tasas de pobreza. 


\section{Cuadro A1.4}

América Latina y el Caribe: indicadores relacionados con la educación, alrededor de 1990, 2000 y 2015

\begin{tabular}{|c|c|c|c|c|c|c|c|c|c|c|c|c|}
\hline & \multicolumn{3}{|c|}{$\begin{array}{c}\text { Tasa de matriculación } \\
\text { en primaria, mujeres } \\
\text { (en porcentajes } \\
\text { de los niños en } \\
\text { edad escolar) }\end{array}$} & \multicolumn{3}{|c|}{$\begin{array}{c}\text { Tasa de matriculación } \\
\text { en primaria, hombres } \\
\text { (en porcentajes } \\
\text { de los niños en } \\
\text { edad escolar) }\end{array}$} & \multicolumn{3}{|c|}{$\begin{array}{c}\text { Tasa de } \\
\text { matriculación en } \\
\text { secundaria, mujeres } \\
\text { (en porcentajes) }\end{array}$} & \multicolumn{3}{|c|}{$\begin{array}{c}\text { Tasa de } \\
\text { matriculación en } \\
\text { secundaria, hombres } \\
\text { (en porcentajes) }\end{array}$} \\
\hline & 1990 & 2000 & 2015 & 1990 & 2000 & 2015 & 1990 & 2000 & 2015 & 1990 & 2000 & 2015 \\
\hline \multicolumn{13}{|l|}{ América del Sur } \\
\hline Argentina & 96,3 & 98,9 & 98,3 & 96,2 & 99,8 & 99,6 & - & 77,2 & 90,3 & - & 72,0 & 84,4 \\
\hline Bolivia (Estado Plurinacional de) & - & 94,3 & 87,0 & - & 95,2 & 88,4 & - & - & 76,2 & - & - & 75,2 \\
\hline Brasil & - & - & - & - & - & - & - & - & - & - & - & - \\
\hline Chile & - & - & 92,4 & - & - & 92,5 & - & - & 90,3 & - & - & 86,9 \\
\hline Colombia & 72,8 & 94,5 & 92,8 & 63,3 & 94,8 & 93,7 & - & - & 80,4 & - & - & 74,1 \\
\hline Ecuador & - & 95,9 & 95,5 & - & 95,1 & 93,8 & - & 48,6 & 84,0 & - & 47,2 & 81,1 \\
\hline Guyana & - & 88,0 & 79,9 & - & 97,0 & 82,8 & - & 72,7 & 82,6 & - & 73,2 & 82,3 \\
\hline Paraguay & 92,1 & 97,7 & 88,3 & 93,8 & 97,1 & 88,8 & 34,3 & 53,6 & 66,3 & 32,4 & 50,9 & 66,6 \\
\hline Perú & 93,3 & 97,5 & 93,1 & 94,2 & 97,9 & 92,5 & - & 63,9 & 79,4 & - & 66,1 & 77,4 \\
\hline Suriname & - & - & 91,8 & - & - & 91,0 & - & - & 50,0 & - & - & 43,9 \\
\hline Uruguay & 92,5 & 92,6 & - & 91,5 & 91,8 & - & - & - & - & - & - & - \\
\hline $\begin{array}{l}\text { Venezuela (República } \\
\text { Bolivariana de) }\end{array}$ & - & 86,2 & 90,6 & - & 85,3 & 90,7 & - & 55,3 & 78,5 & - & 45,8 & 71,2 \\
\hline \multicolumn{13}{|l|}{ Centroamérica } \\
\hline Belice & - & 94,0 & 95,5 & - & 95,6 & 97,6 & - & 60,2 & 71,1 & - & 57,0 & 67,3 \\
\hline Costa Rica & 88,0 & - & 96,1 & 87,5 & - & 96,2 & 38,7 & - & 80,1 & 36,4 & - & 76,2 \\
\hline El Salvador & - & 90,3 & 94,7 & - & 90,9 & 94,6 & - & 47,5 & 70,1 & - & 48,6 & 69,0 \\
\hline Guatemala & - & 80,8 & 86,1 & - & 86,9 & 86,7 & - & 24,3 & 45,4 & - & 26,9 & 48,0 \\
\hline Honduras & 88,7 & 89,0 & 94,2 & 87,6 & 88,1 & 93,9 & - & - & 53,0 & - & - & 45,7 \\
\hline México & - & 96,9 & 96,0 & - & 96,3 & 95,3 & - & 59,6 & 68,8 & - & 57,8 & 66,1 \\
\hline Nicaragua & 69,2 & 82,7 & 98,0 & 65,9 & 80,8 & 95,9 & - & 40,8 & 53,0 & - & 33,5 & 45,1 \\
\hline Panamá & 86,8 & 95,0 & 95,5 & 86,4 & 95,4 & 96,3 & - & 61,2 & 80,6 & - & 55,5 & 75,2 \\
\hline \multicolumn{13}{|l|}{ El Caribe } \\
\hline Antigua y Barbuda & - & - & 83,2 & - & - & 86,7 & - & 66,6 & 81,3 & - & 72,0 & 78,2 \\
\hline Bahamas & 88,9 & 89,9 & 98,62 & 88,2 & 91,6 & 93,21 & 90,4 & 70,4 & 85,68 & 87,9 & 71,2 & 79,74 \\
\hline Barbados & 96,7 & 95,5 & 92,0 & 98,5 & 95,5 & 90,1 & 73,7 & 91,3 & 100,0 & 84,0 & 92,5 & 98,9 \\
\hline Bermuda & - & - & 81,5 & - & - & 85,3 & - & - & 78,6 & - & - & 67,9 \\
\hline Cuba & 92,5 & 96,1 & 93,5 & 92,5 & 97,2 & 92,8 & 72,0 & 82,3 & 91,1 & 67,1 & 80,0 & 87,9 \\
\hline Dominica & - & - & - & - & - & - & - & 89,5 & 81,5 & - & 78,2 & 76,5 \\
\hline Granada & - & 93,7 & 89,5 & - & 95,1 & 91,5 & - & 91,2 & 80,9 & - & 76,1 & 79,6 \\
\hline Haití & - & 56,9 & - & - & 57,8 & - & - & - & - & - & - & - \\
\hline Jamaica & 98,4 & 92,1 & - & 98,1 & 92,5 & - & - & 78,5 & 77,5 & - & 76,1 & 69,7 \\
\hline Puerto Rico & - & - & 83,3 & - & - & 80,0 & - & - & 77,2 & - & - & 72,3 \\
\hline República Dominicana & - & 83,7 & 82,6 & - & 83,2 & 84,5 & - & 44,2 & 69,8 & - & 35,7 & 61,2 \\
\hline Saint Kitts y Nevis & - & 95,7 & 80,2 & - & 93,4 & 77,8 & 80,0 & 98,9 & 84,7 & 78,0 & 92,9 & 81,2 \\
\hline San Vicente y las Granadinas & - & - & 84,8 & - & - & 86,6 & - & 78,4 & 86,5 & - & 57,6 & 83,9 \\
\hline Santa Lucía & 95,9 & 87,1 & - & 98,7 & 91,4 & - & - & 69,5 & 81,2 & - & 54,8 & 80,2 \\
\hline Trinidad y Tabago & 91,9 & 93,8 & 94,8 & 88,2 & 93,9 & 95,7 & 68,0 & 75,2 & - & 65,7 & 70,2 & - \\
\hline
\end{tabular}

Fuente: Banco Mundial, World Development Indicators, 2016 [base de datos en línea] http://data.worldbank.org/datacatalog/ world-development-indicators.

Nota: En los casos en que no se dispone de datos correspondientes al año exacto, las cifras indicadas en el cuadro se refieren a los años cercanos. En varios países del Caribe no se dispone de datos sobre las tasas de pobreza. 
Cuadro A1.5

América Latina y el Caribe: acceso al agua, alrededor de 1990, 2000 y 2015

(En porcentajes)

\begin{tabular}{|c|c|c|c|c|c|c|}
\hline & \multicolumn{3}{|c|}{ Acceso al agua: población zonas urbanas } & \multicolumn{3}{|c|}{ Acceso al agua: población zonas rurales } \\
\hline & 1990 & 2000 & 2015 & 1990 & 2000 & 2015 \\
\hline \multicolumn{7}{|l|}{ América del Sur } \\
\hline Argentina & 97,5 & 98,1 & 99,0 & 68,8 & 81,3 & 100 \\
\hline Bolivia (Estado Plurinacional de) & 90,5 & 93,1 & 96,7 & 40,4 & 55,1 & 75,6 \\
\hline Brasil & 95,8 & 97,6 & 100 & 67,7 & 75,7 & 87,0 \\
\hline Chile & 98,9 & 99,2 & 99,7 & 48,2 & 67,8 & 93,3 \\
\hline Colombia & 97,5 & 97,2 & 96,8 & 68,8 & 71,0 & 73,8 \\
\hline Ecuador & 83,9 & 87,9 & 93,4 & 61,4 & 67,3 & 75,5 \\
\hline Guyana & 92,6 & 94,5 & 98,2 & 73,6 & 81,8 & 98,3 \\
\hline Paraguay & 84,9 & 91,0 & 100 & 22,7 & 51,6 & 94,9 \\
\hline Perú & 88,0 & 89,4 & 91,4 & 43,9 & 54 & 69,2 \\
\hline Suriname & 97,8 & 97,8 & 98,1 & - & 72,5 & 88,4 \\
\hline Uruguay & 97,8 & 98,5 & 100 & 70,3 & 77,0 & 93,9 \\
\hline Venezuela (República Bolivariana de) & 92,6 & 93,6 & 95,0 & 68,4 & 72,5 & 77,9 \\
\hline \multicolumn{7}{|l|}{ Centroamérica } \\
\hline Belice & 87,4 & 92,4 & 98,9 & 59,8 & 78,5 & 100 \\
\hline Costa Rica & 99,2 & 99,4 & 99,6 & 86,5 & 88,8 & 91,9 \\
\hline El Salvador & 90,4 & 93,3 & 97,5 & 50,6 & 65,0 & 86,5 \\
\hline Guatemala & 89,8 & 93,6 & 98,4 & 67,5 & 75,9 & 86,8 \\
\hline Honduras & 92,4 & 94,4 & 97,4 & 59,9 & 69,5 & 83,8 \\
\hline México & 91,5 & 94,1 & 97,2 & 59,4 & 74,4 & 92,1 \\
\hline Nicaragua & 90,6 & 94,4 & 99,3 & 53,0 & 60,1 & 69,4 \\
\hline Panamá & 97,8 & 97,8 & 97,7 & 67,5 & 75,9 & 88,6 \\
\hline \multicolumn{7}{|l|}{ El Caribe } \\
\hline Antigua y Barbuda & 97,4 & 97,7 & 97,9 & 97,4 & 97,7 & 97,9 \\
\hline Bahamas & 96,3 & 96,6 & 98,4 & 96,3 & 96,6 & 98,4 \\
\hline Barbados & 96,1 & 97,6 & 99,7 & 96,1 & 97,6 & 99,7 \\
\hline Bermuda & - & - & - & - & - & - \\
\hline Cuba & 93,9 & 94,9 & 96,4 & - & 77,3 & 89,8 \\
\hline Dominica & 95,7 & 95,7 & 95,7 & - & 91,8 & - \\
\hline Granada & 99,0 & 99 & 99 & 95,3 & 95,3 & 95,3 \\
\hline Haití & 91,2 & 81,6 & 64,9 & 50,2 & 49,3 & 47,6 \\
\hline Islas Caimán & 92,3 & 93,3 & 97,4 & - & - & - \\
\hline Islas Turcas y Caicos & 87,1 & 87,1 & - & 87,0 & 87,0 & - \\
\hline Islas Vírgenes de los Estados Unidos & 100 & 100 & 100 & 100 & 100 & 100 \\
\hline Islas Vírgenes Británicas & 94,8 & 94,9 & - & 94,8 & 94,9 & - \\
\hline Jamaica & 97,9 & 97,7 & 97,5 & 88,5 & 88,9 & 89,4 \\
\hline Puerto Rico & 93,6 & 93,6 & - & 93,6 & 93,6 & - \\
\hline República Dominicana & 96,7 & 92,2 & 85,4 & 75,8 & 78,2 & 81,9 \\
\hline Saint Kitts y Nevis & 98,3 & 98,3 & 98,3 & 98,3 & 98,3 & 98,3 \\
\hline San Vicente y las Granadinas & 88,2 & 93,5 & 95,1 & 88,2 & 93,5 & 95,1 \\
\hline Santa Lucía & 95,4 & 97,1 & 99,5 & 91,3 & 93,1 & 95,6 \\
\hline Trinidad y Tabago & 91,6 & 93,3 & 95,0 & 91,6 & 93,3 & 95,0 \\
\hline
\end{tabular}

Fuente: Banco Mundial, World Development Indicators, 2016 [base de datos en línea] http://data.worldbank.org/datacatalog/ world-development-indicators.

Nota: En los casos en que no se dispone de datos correspondientes al año exacto, las cifras indicadas en el cuadro se refieren a los años cercanos. En varios países del Caribe no se dispone de datos sobre las tasas de pobreza. 
Cuadro A1.6

América Latina y el Caribe: indicadores relacionados con el empleo, alrededor de 1990, 2000 y 2015

(En porcentajes)

\begin{tabular}{|c|c|c|c|c|c|c|c|c|c|c|c|c|}
\hline & \multicolumn{3}{|c|}{$\begin{array}{l}\text { Desempleo } \\
\text { (total) }\end{array}$} & \multicolumn{3}{|c|}{$\begin{array}{l}\text { Desempleo } \\
\text { (hombres) }\end{array}$} & \multicolumn{3}{|c|}{$\begin{array}{c}\text { Desempleo } \\
\text { (mujeres) }\end{array}$} & \multicolumn{3}{|c|}{ Empleo informal $^{\mathrm{a}}$} \\
\hline & 1990 & 2000 & 2015 & 1990 & 2000 & 2015 & 1990 & 2000 & 2015 & 1990 & 2000 & 2015 \\
\hline \multicolumn{13}{|l|}{ América del Sur } \\
\hline Argentina & 5,8 & 15,0 & 8,2 & 5,4 & 13,7 & 7,1 & 6,4 & 17,1 & 9,8 & 45,0 & 42,0 & 47,1 \\
\hline Bolivia (Estado Plurinacional de) & 2,9 & 4,8 & 2,7 & 2,4 & 4,0 & 2,2 & 3,8 & 5,9 & 3,3 & - & - & 71,8 \\
\hline Brasil & 6,9 & 9,5 & 6,8 & 5,3 & 7,7 & 5,2 & 9,6 & 12,0 & 8,7 & 41,9 & 46,6 & 36,8 \\
\hline Chile & 8,1 & 9,2 & 6,4 & 7,3 & 8,8 & 5,8 & 10,1 & 10,1 & 7,3 & 33,7 & 33,1 & - \\
\hline Colombia & 13,9 & 16,6 & 10,1 & 11,5 & 13,0 & 7,7 & 19,6 & 22,2 & 13,3 & 50,0 & 60,9 & 63,7 \\
\hline Ecuador & 4,0 & 7,2 & 4,6 & 3,4 & 5,4 & 3,5 & 5,2 & 10,1 & 6,2 & - & 48,1 & - \\
\hline Guyana & 12,0 & 11,5 & 11,1 & 9,4 & 9,8 & 9,6 & 17,4 & 15,1 & 14,0 & - & - & - \\
\hline Paraguay & 6,5 & 7,6 & 4,5 & 5,4 & 6,7 & 3,8 & 8,5 & 9,2 & 5,6 & - & - & 64,4 \\
\hline Perú & 6,0 & 6,4 & 4,2 & 5,5 & 6,1 & 3,7 & 6,9 & 6,8 & 4,8 & - & - & 68,8 \\
\hline Suriname & 10,6 & 14,8 & 5,6 & 8,3 & 11,7 & 3,6 & 14,8 & 20,6 & 8,9 & - & - & - \\
\hline Uruguay & 7,0 & 10,7 & 7,0 & 5,4 & 7,9 & 5,3 & 9,5 & 14,5 & 9,1 & - & 40,3 & - \\
\hline $\begin{array}{l}\text { Venezuela (República } \\
\text { Bolivariana de) }\end{array}$ & 9,5 & 13,2 & 8,6 & 8,8 & 12,6 & 8,1 & 10,9 & 14,3 & 9,4 & - & - & - \\
\hline \multicolumn{13}{|l|}{ Centroamérica } \\
\hline Belice & 10,8 & 10,9 & 11,5 & 7,9 & 8,0 & 6,5 & 17,6 & 16,9 & 19,7 & - & - & - \\
\hline Costa Rica & 5,6 & 5,1 & 8,3 & 4,8 & 4,3 & 6,7 & 7,7 & 6,8 & 11,0 & 36,5 & 35,4 & 30,7 \\
\hline El Salvador & 6,5 & 7,0 & 6,2 & 7,9 & 8,6 & 7,4 & 4,0 & 4,5 & 4,4 & - & - & 65,4 \\
\hline Guatemala & 3,2 & 1,4 & 2,9 & 3,2 & 1,2 & 2,8 & 3,3 & 1,8 & 3,0 & - & - & 74,4 \\
\hline Honduras & 4,7 & 3,9 & 3,9 & 4,0 & 3,8 & 3,3 & 6,4 & 4,1 & 5,1 & 47,2 & 60,9 & 73,4 \\
\hline México & 3,0 & 2,5 & 4,9 & 2,5 & 2,1 & 4,9 & 4,2 & 3,2 & 5,0 & - & - & 53,9 \\
\hline Nicaragua & 4,7 & 6,2 & 5,3 & 4,7 & 7,4 & 5,3 & 4,7 & 3,7 & 5,3 & - & 57,0 & - \\
\hline Panamá & 16,1 & 13,5 & 4,3 & 12,8 & 11,1 & 3,6 & 22,7 & 17,8 & 5,6 & 33,3 & 32,8 & - \\
\hline \multicolumn{13}{|l|}{ El Caribe } \\
\hline Bahamas & 12,2 & 7,2 & 15,4 & 12,4 & 5,7 & 15,1 & 12,0 & 8,8 & 15,7 & - & - & - \\
\hline Barbados & 17,1 & 9,3 & 12,0 & 13,5 & 7,3 & 9,9 & 21,1 & 11,6 & 14,3 & - & - & - \\
\hline Bermuda & - & - & - & - & - & - & - & - & - & - & - & - \\
\hline Cuba & 2,3 & 5,4 & 3,3 & 2,1 & 4,9 & 2,9 & 2,7 & 6,4 & 3,9 & - & - & - \\
\hline Haití & 11,4 & 7,4 & 6,8 & 8,6 & 6,4 & 5,9 & 14,8 & 8,5 & 7,8 & - & - & - \\
\hline Jamaica & 15,7 & 15,5 & 13,2 & 9,7 & 10,0 & 9,7 & 22,6 & 22,4 & 17,3 & - & - & - \\
\hline Puerto Rico & 17,1 & 10,3 & 14,3 & 18,9 & 12,1 & 16,1 & 13,7 & 7,5 & 11,9 & - & - & - \\
\hline República Dominicana & 19,9 & 14,2 & 15,0 & 12,9 & 8,8 & 9,5 & 33,5 & 23,6 & 23,4 & - & - & 51,4 \\
\hline Trinidad y Tabago & 18,5 & 12,1 & 4,0 & 15,7 & 10,2 & 3,1 & 22,7 & 15,1 & 5,3 & - & - & - \\
\hline
\end{tabular}

Fuente: Banco Mundial, World Development Indicators, 2016 [base de datos en línea] http://data.worldbank.org/datacatalog/ world-development-indicators.

Nota: En los casos en que no se dispone de datos correspondientes al año exacto, las cifras indicadas en el cuadro se refieren a los años cercanos. En varios países del Caribe no se dispone de datos sobre las tasas de pobreza.

a Porcentajes del empleo total no agrícola. 
Cuadro A1.7

América Latina y el Caribe:

índice de desarrollo humano, 1990, 2000 y 2015

\begin{tabular}{|c|c|c|c|}
\hline & \multicolumn{3}{|c|}{ Índice de desarrollo humano } \\
\hline & 1990 & 2000 & 2015 \\
\hline \multicolumn{4}{|l|}{ América del Sur } \\
\hline Argentina & 0,71 & 0,76 & 0,84 \\
\hline Bolivia (Estado Plurinacional de) & 0,54 & 0,60 & 0,66 \\
\hline Brasil & 0,61 & 0,68 & 0,76 \\
\hline Chile & 0,69 & 0,75 & 0,83 \\
\hline Colombia & 0,59 & 0,65 & 0,72 \\
\hline Ecuador & 0,65 & 0,70 & 0,77 \\
\hline Guyana & 0,54 & 0,60 & 0,64 \\
\hline Paraguay & 0,58 & 0,62 & 0,68 \\
\hline Perú & 0,61 & 0,68 & 0,73 \\
\hline Suriname & - & - & 0,71 \\
\hline Uruguay & 0,69 & 0,74 & 0,79 \\
\hline Venezuela (República Bolivariana de) & 0,64 & 0,67 & 0,76 \\
\hline \multicolumn{4}{|l|}{ Centroamérica } \\
\hline Belice & 0,64 & 0,68 & 0,72 \\
\hline Costa Rica & 0,65 & 0,70 & 0,77 \\
\hline El Salvador & 0,52 & 0,60 & 0,66 \\
\hline Guatemala & 0,48 & 0,55 & 0,63 \\
\hline Honduras & 0,51 & 0,56 & 0,61 \\
\hline México & 0,65 & 0,70 & 0,76 \\
\hline Nicaragua & 0,50 & 0,57 & 0,63 \\
\hline Panamá & 0,66 & 0,68 & 0,78 \\
\hline \multicolumn{4}{|l|}{ El Caribe } \\
\hline Antigua y Barbuda & - & - & 0,78 \\
\hline Bahamas & - & 0,78 & 0,79 \\
\hline Barbados & 0,71 & 0,75 & 0,79 \\
\hline Cuba & 0,67 & 0,69 & 0,77 \\
\hline Dominica & - & 0,69 & 0,72 \\
\hline Granada & - & - & 0,75 \\
\hline Haití & 0,42 & 0,44 & 0,48 \\
\hline Jamaica & 0,67 & 0,70 & 0,72 \\
\hline República Dominicana & 0,57 & 0,65 & 0,72 \\
\hline Saint Kitts y Nevis & - & - & 0,75 \\
\hline San Vicente y las Granadinas & - & - & 0,72 \\
\hline Santa Lucía & - & - & 0,73 \\
\hline Trinidad y Tabago & 0,67 & 0,72 & 0,77 \\
\hline
\end{tabular}

Fuente: Programa de las Naciones Unidas para el Desarrollo (PNUD), Informe sobre Desarrollo Humano 2016: desarrollo humano para todas las personas, Nueva York, 2016. 
Cuadro A1.8

América Latina y el Caribe: índice de desarrollo relativo al género, 2014

\begin{tabular}{|c|c|c|c|c|c|c|}
\hline & \multicolumn{2}{|c|}{$\begin{array}{l}\text { Índice de desarrollo } \\
\text { relativo al género }\end{array}$} & \multirow{2}{*}{\multicolumn{2}{|c|}{$\begin{array}{c}\text { Índice de desarrollo humano } \\
\text { Valor }\end{array}$}} & \multicolumn{2}{|c|}{$\begin{array}{l}\text { Índice de desigualdad } \\
\text { de género }\end{array}$} \\
\hline & \multirow{2}{*}{ Valor } & \multirow{2}{*}{ Grupo } & & & Valor & Puecto \\
\hline & & & Mujeres & Hombres & valui & ruesto \\
\hline & 2014 & 2014 & 2014 & 2014 & 2014 & 2014 \\
\hline \multicolumn{7}{|l|}{ América del Sur } \\
\hline Argentina & 0,982 & 1 & 0,819 & 0,834 & 0,376 & 75 \\
\hline Bolivia (Estado Plurinacional de) & 0,931 & 3 & 0,637 & 0,684 & 0,444 & 94 \\
\hline Brasil & 0,997 & 1 & 0,752 & 0,754 & 0,457 & 97 \\
\hline Chile & 0,967 & 2 & 0,815 & 0,843 & 0,338 & 65 \\
\hline Colombia & 0,997 & 1 & 0,719 & 0,721 & 0,429 & 92 \\
\hline Ecuador & 0,980 & 1 & 0,722 & 0,737 & 0,407 & 83 \\
\hline Guyana & 0,984 & 1 & 0,626 & 0,636 & 0,515 & 114 \\
\hline Paraguay & 0,956 & 2 & 0,662 & 0,692 & 0,472 & 101 \\
\hline Perú & 0,947 & 3 & 0,712 & 0,752 & 0,406 & 82 \\
\hline Suriname & 0,975 & 1 & 0,702 & 0,720 & 0,463 & 100 \\
\hline Uruguay & 1,018 & 1 & 0,797 & 0,783 & 0,313 & 61 \\
\hline Venezuela (República Bolivariana de) & 1,030 & 2 & 0,772 & 0,749 & 0,476 & 103 \\
\hline \multicolumn{7}{|l|}{ Centroamérica } \\
\hline Belice & 0,958 & 2 & 0,696 & 0,727 & 0,426 & 90 \\
\hline Costa Rica & 0,974 & 2 & 0,753 & 0,774 & 0,349 & 66 \\
\hline El Salvador & 0,965 & 2 & 0,652 & 0,676 & 0,427 & 91 \\
\hline Guatemala & 0,949 & 3 & 0,608 & 0,641 & 0,533 & 119 \\
\hline Honduras & 0,944 & 3 & 0,583 & 0,618 & 0,480 & 106 \\
\hline México & 0,943 & 3 & 0,731 & 0,775 & 0,373 & 74 \\
\hline Nicaragua & 0,960 & 2 & 0,615 & 0,640 & 0,449 & 95 \\
\hline Panamá & 0,996 & 1 & 0,776 & 0,779 & 0,454 & 96 \\
\hline \multicolumn{7}{|l|}{ El Caribe } \\
\hline Antigua y Barbuda & - & - & - & - & - & - \\
\hline Bahamas & - & - & - & - & 0,298 & 58 \\
\hline Barbados & 1,018 & 1 & 0,791 & 0,777 & 0,357 & 69 \\
\hline \multicolumn{7}{|l|}{ Bermuda } \\
\hline Cuba & 0,954 & 2 & 0,747 & 0,783 & 0,356 & 68 \\
\hline Dominica & - & - & - & - & - & - \\
\hline Granada & - & - & - & - & - & - \\
\hline Haití & - & - & - & - & 0,603 & 138 \\
\hline Islas Caimán & - & - & - & - & - & - \\
\hline Islas Turcas y Caicos & - & - & - & - & - & - \\
\hline Islas Vírgenes de los Estados Unidos & - & - & - & - & - & - \\
\hline Islas Vírgenes Británicas & - & - & - & - & - & - \\
\hline Jamaica & 0,995 & 1 & 0,715 & 0,719 & 0,430 & 93 \\
\hline Puerto Rico & - & - & - & - & - & - \\
\hline República Dominicana & 0,995 & 1 & 0,710 & 0,713 & 0,477 & 104 \\
\hline Saint Kitts y Nevis & - & - & - & - & - & - \\
\hline San Vicente y las Granadinas & - & - & - & - & - & - \\
\hline Santa Lucía & 0,991 & 1 & 0,725 & 0,731 & - & - \\
\hline Trinidad y Tabago & 0,985 & 1 & 0,763 & 0,774 & 0,371 & 73 \\
\hline
\end{tabular}

Fuente: Programa de las Naciones Unidas para el Desarrollo (PNUD), Informe sobre Desarrollo Humano 2016: desarrollo humano para todas las personas, Nueva York, 2016.

Nota: Todos los países de América Latina y el Caribe disponibles en el conjunto de datos (aunque estén incompletos). 


\section{Cuadro A1.9}

América Latina y el Caribe: índice de pobreza multidimensional (IPM), último año disponible

\begin{tabular}{|c|c|c|c|}
\hline & \multicolumn{3}{|c|}{$\begin{array}{c}\text { Índice de pobreza multidimensional } \\
\text { (Oficina del Informe sobre Desarrollo Humano) }\end{array}$} \\
\hline & Año & $\begin{array}{c}\text { Incidencia } \\
\text { (en porcentajes) }\end{array}$ & Intensidad $^{\mathrm{a}}$ \\
\hline \multicolumn{4}{|l|}{ América del Sur } \\
\hline Argentina & 2005 & 3,7 & 39,1 \\
\hline Bolivia (Estado Plurinacional de) & 2008 & 20,6 & 47 \\
\hline Brasil & 2013 & 2,9 & 40,2 \\
\hline Colombia & 2010 & 7,6 & 42,2 \\
\hline Ecuador & $2013 / 2014$ & 3,7 & 39,6 \\
\hline Guyana & 2009 & 7,8 & 40 \\
\hline Perú & 2012 & 10,4 & 41,4 \\
\hline Suriname & 2010 & 7,6 & 43,1 \\
\hline \multicolumn{4}{|l|}{ Centroamérica } \\
\hline Belice & 2011 & 7,4 & 41,2 \\
\hline Honduras & $2011 / 2012$ & 20,7 & 47,4 \\
\hline México & 2012 & 6 & 39,9 \\
\hline Nicaragua & $2011 / 2012$ & 19,4 & 45,6 \\
\hline \multicolumn{4}{|l|}{ El Caribe } \\
\hline Barbados & 2012 & 0,9 & 33,7 \\
\hline Haití & 2012 & 50,2 & 48,1 \\
\hline Jamaica & 2010 & 3,7 & 38,8 \\
\hline República Dominicana & 2013 & 6 & 4,6 \\
\hline Santa Lucía & 2012 & 0,8 & 34,5 \\
\hline Trinidad y Tabago & 2006 & 1,7 & 38 \\
\hline
\end{tabular}

Fuente: Programa de las Naciones Unidas para el Desarrollo (PNUD), Informe sobre Desarrollo Humano 2016: desarrollo humano para todas las personas, Nueva York, 2016.

a Promedio ponderado del número de carencias que las personas en situación de pobreza sufren al mismo tiempo. 